UNIVERSITY OF GOTHENBURG

SCHOOL OF BUSINESS, ECONOMICS AND LAW

WORKING PAPERS IN ECONOMICS

No 512

The Impact of Legalized Abortion on

Child Health Outcomes and Abandonment.

Evidence from Romania

by

Andreea Mitrut and Francois-Charles Wolff

August 2011

ISSN 1403-2473 (print)

ISSN 1403-2465 (online)

Department of Economics

School of Business, Economics and Law at University of Gothenburg

Vasagatan 1, PO Box 640, SE 40530 Göteborg, Sweden

+46 31786 0000, +46317861326 (fax)

www.handels.gu.se info@handels.gu.se 


\title{
The Impact of Legalized Abortion on Child Health Outcomes and Abandonment. Evidence from Romania ${ }^{\#}$
}

\author{
Andreea Mitrut ${ }^{\dagger}$ and François-Charles Wolff *
}

\begin{abstract}
We use household survey data and a unique census of institutionalized children to analyze the impact of abortion legalization in Romania. We exploit the lift of the abortion ban in December 1989, when communist dictator Ceausescu and his regime were removed from power, to understand its impact on children's health at birth and during early childhood and whether the lift of the ban had an immediate impact on child abandonment. We find insignificant estimates for health at birth outcomes and anthropometric z-scores at age 4 and 5 , except for the probability of low birth weight which is slightly higher for children born after abortion became legal. Additionally, our findings suggest that the lift of the ban had decreased the number of abandoned children.
\end{abstract}

Keywords: abortion; health; anthropometric outcomes; child abandonment; Romania

JEL classification: I12, J13

\footnotetext{
${ }^{\text {\# }}$ We are indebted to our editor and two anonymous reviewers for their very helpful remarks and suggestions on a previous draft. We have also benefited from input from Lennart Flood and Olof Johansson-Stenman, and from seminar participants at Uppsala University, Örebro University, INED, Angers (Journée de Microéconomie Appliquée) and University of Reims (Workshop Response). We are indebted to the Romanian National Institute of Statistics and the World Bank for making the data available. The usual disclaimer applies.

${ }^{\dagger}$ Corresponding author. Department of Economics, Uppsala University and UCLS, Uppsala Center for Labor Studies; Department of Economics, University of Gothenburg; the Bucharest Academy of Economic Studies. E-mail: Andreea.Mitrut@nek.uu.se; Address: Box 513, SE-75120, Uppsala, Sweden.

${ }^{\ddagger}$ LEMNA, Université de Nantes, France; CNAV and INED, Paris, France.

E-mail: francois.wolff@univ-nantes.fr http://www.sc-eco.univ-nantes.fr/ fcwolff
} 


\section{Introduction}

Abortion legalization is, by far, one of the most controversial public policies around the world. Using the 1973 Roe v. Wade Supreme Court decision to legalize abortion in the US, several studies have examined the characteristics of cohorts born before and after this policy came into effect. The main conclusion is that abortion availability has, on average, lead to an improvement in the socio-economic outcomes of the cohorts of children born after the change. In particular, they are less likely to be living with a single parent or in poverty, to be receiving welfare and die as infants (Gruber et al., 1999), less likely to commit crimes (Donohue and Levitt, 2001, 2004), less likely to use controlled substances as teens (Charles and Stephens, 2006), and they have lower teen childbirth and out-of-wedlock childbearing rates (Angrist and Evans, 1999). Some of these findings remain somewhat controversial. For instance, Foote and Goetz (2008) recently casted doubt on the relevance of the causal link suggested by Donohue and Levitt (2001) between legalization of abortion and the decline in crime during the 1990s in the US.

Apart from the studies on the US, there is very limited evidence on a causal link between access to abortion and socio-economic outcomes of children. One exception in the context of a transitional economy is Pop-Eleches (2006), who finds that children born immediately after abortion became illegal in Romania display worse educational and labor market outcomes later on in life than do children born prior to this policy change. ${ }^{1}$ Starting in 1966, Romanian communist authorities drastically restricted abortion and made family planning illegal. This was one of the most restrictive anti-abortion laws and one of the toughest in the world. ${ }^{2}$ Abortion and family planning remained illegal until December 1989 when the communist dictator Nicolae Ceausescu was killed and his regime was removed from power.

In this paper, we use this unexpected policy change as a natural experiment to assess the impact of abortion legalization on several children-related outcomes and on child abandonment. Our first aim is to use the lift of the abortion ban in Romania to assess the causal impact of abortion legalization on children's health status. Our main outcome of interest is health at birth measured by children's birth weight and low birth weight. Additionally, we examine the impact of the abortion legalization on early childhood

\footnotetext{
${ }^{1}$ Additionally, using aggregate data, Pop-Eleches (2006) provides evidence that the abortion ban influenced early infant outcomes, i.e., increased infant mortality and the percentage of low birth weight, from 1966 to 1968.

${ }^{2}$ Romanian women without children paid a "celibacy tax" of up to 10 percent from their monthly salaries, while women of childbearing were forced to undergo monthly gynecological exams at workplaces and schools (Greenwell, 2003).
} 
malnutrition and stunting measured by height-for-age and weight-for-height $\mathrm{z}$-scores. Understanding health outcomes early in life is crucial since poor health at birth (typically observed as low birth weight) and/or during early childhood (typically measured by anthropometric z-scores) has, on average, adverse long-term consequences such as poor school performance and lower labor market achievements in adult life (Almond and Currie, 2010; Case et al., 2002, 2005; Smith, 1998, 2009).

Our second aim is to investigate the effect of the unexpected change in abortion policy on child abandonment, one of the most shocking outcomes of the abortion ban in communist Romania. The complex factors that initiated child abandonment started in 1966, when the authorities restricted abortion and intensified in the 1980s when the centralized distribution affected families' abilities to cover basic needs such as eating, heating or lighting their homes. In particular, starting in 1970's, parents were placing their children in state-run institutions, either as a temporary measure or permanently, in the form of abandonment (see Mitrut, 2008). These children were deprived of adequate care and opportunities for emotional and social development. ${ }^{3}$ While the magnitude of this phenomenon before 1989 remains unknown, it is believed that about $2-4 \%$ of the total Romanian population aged $0-18$ were institutionalized in early 1990s (UNICEF, 2007). Our prior is that if abortion availability reduces the number of unwanted or unplanned children, one may expect a lower rate of child abandonment immediately after abortion is legalized. ${ }^{4}$

We investigate the consequences of the lift of abortion ban using two different data sets. First, we study whether health outcomes have improved among children born after the lift of the ban using the first two waves (1994-95 and 1995-96) of the Romanian Integrated Household Survey. These are the first representative Romanian data sets that, in addition to the standard socio-economic information, include anthropometric measures such as birth weight, current weight, and height/length for children 0-60 months of age at the time of the survey. Secondly, we document the relationship between abortion ban and child abandonment using a unique census data covering all state institutionalized children in Romania in $1997 .{ }^{5}$

Our empirical strategy relies on the fact that the unexpected legalization of abortion in December 1989 led to an immediate reduction in the number of births about six months later,

\footnotetext{
${ }^{3}$ Children that were previously institutionalized and subsequently adopted or placed in family-base care have reduced cognitive, physical, behavioral, and social emotional ability (Nelson et al., 2007; Maclean, 2003; Johnson, 2000).

${ }^{4}$ Bitler and Zavodny (2002) find for instance that abortion legalization in the US lowered the rates on child abuse and neglect.

${ }^{5}$ Institutionalized children were not part of the Romanian census or any other official surveys in Romania.
} 
in July 1990. This pattern was expected since women who were in their second or third trimester could not make use of the abortion legalization because, under the new liberal law, abortion was only allowed during the first trimester of pregnancy. Thus, children born July 1990-December 1990 were born under a liberal abortion policy if compared to those born January-June 1990.

We study health outcomes and child abandonment using two different empirical frameworks. First, we draw on a before-after strategy and calculate simple differences between the outcomes for children born immediately before and immediately after July 1990. Secondly, we consider a difference-in-difference strategy. The idea is that even though we may observe an improvement in outcomes among children born during the $2^{\text {nd }}$ semester in 1990 (JulyDecember) relative to those born during the $1^{\text {st }}$ semester (January-June), this could be because health outcomes are not orthogonal to calendar effects (van Hanswijck de Jonge et al., 2003; Loskin and Radyakin, 2009). However, if this is the case, then we should observe a similar tendency for those born during the $2^{\text {nd }}$ and $1^{\text {st }}$ semesters in 1991.

Overall, we find insignificant estimates for health at birth except for the probability of low birth weight which is slightly higher for children born after abortion became legal. Similarly, the pattern of our estimates for weight-for-height and height-for-age z-scores is positive, but these estimates are not statistically significant. With respect to child abandonment, our findings suggest that the lift of the abortion ban has decreased the number of abandoned children in the total live births. Using regional variation in fertility and child abandonment, we calculate that the immediate impact of the policy change was a decrease of about 4 abandoned children per 10,000 live births.

The remainder of our paper is organized as follows. Section 2 discusses the theoretical mechanisms through which the abortion ban is expected to have influenced children's outcomes. Section 3 explains the Romanian context and describes our data. The estimation strategy is presented in Section 4. Estimates for weight at birth and anthropometric z-scores are described in Section 5, while in Section 6 we address the issue of child abandonment. Finally, Section 7 concludes. 


\section{The mechanisms through which an abortion ban may affect children's outcomes}

There are three main possible mechanisms through which an abortion ban may affect children's outcomes (see also Pop-Eleches, 2006, 2009). First, changes in access to abortion may influence the number of unplanned or unwanted children (the so-called unwantedness effect), which, in turn, should affect children as follows:

(1) the standard model of child quality-quantity trade-off predicts that an increase in the number of children as a result of an unwanted pregnancy may lead to a decrease in child quality (Becker, 1981; Becker and Lewis, 1973);

(2) when access to birth control methods is limited, women are less able to postpone their childbearing to an optimal time, which may be inconsistent with their long-term educational and labor market plans, which in turn may have negative effects on children (Angrist and Evans, 1999); ${ }^{6}$

(3) lack of access to abortion may have a negative influence on fetal health through at least two important channels: $a$ ) it may not allow parents to end a pregnancy based on fetal health and $b$ ) it may lead to delayed and/or unhealthy prenatal care due to unwantedness (Grossman and Jacobowitz, 1981; Rosenzweig and Schultz, 1983; Grossman and Joyce, 1990). ${ }^{7}$

Secondly, another key process that may affect the average socio-economic outcomes of children is the composition of women who are more likely to carry pregnancies to term. There is no theoretical consensus on the direction of this effect and the empirical evidence is also quite mixed. In the US, the marginal users of abortion were women from more disadvantaged socio-economic backgrounds and therefore they were more likely to be affected by the policy change, further suggesting an increase in the average outcome of the children born following legalization of abortion (Gruber et al., 1999). Exploring the Romanian cohorts born before and after the 1966 abortion ban, Pop-Eleches (2006) finds that children born after the abortion ban are actually better-off in terms of education and labor market outcomes. This surprising effect is due to the composition of women more likely to have an abortion prior to the ban. On average, women living in urban areas and highly educated women were more likely to have an abortion in Romania prior to the 1966 policy change.

\footnotetext{
${ }^{6}$ In addition, involuntary parenthood may influence the mother's and/or the father's physical well-being, which may affect the development of the child in utero and within the family.

${ }^{7}$ Additionally, young teenagers (13 to 17 years) have a higher risk of low birth weight babies and premature and small for gestational age births (Fraser et al., 1995). Advanced maternal age ( $>35$ years) is also considered as a risk factor for low birth weight and stillbirths (Jolly et al., 2000).
} 
Once controlling for this composition effect using observable background characteristics, the pattern is reversed and the abortion ban indeed decreases the long-term outcomes of Romanian children (as expected). Conversely, when turning to the effect of the 1989 legalization of abortion and access to birth control methods on children's educational outcomes, Pop-Eleches (2009) finds that the composition effect of women is similar to the pattern seen in the US during the 1970s: women from more disadvantaged socio-economic backgrounds are more likely to experience reduced fertility.

Thirdly, in addition to the unwantedness and the composition effects, changes in cohort size may also affect educational and/or health outcomes because of changes in the crowding of a country's educational and/or health resources. For instance, Romanian children born in 1967 went to school with a cohort that was more than twice as large as the 1966 cohort, hence the mean amount of public expenditures per child was most likely reduced (Pop-Eleches, 2006). This kind of reduction can be expected to influence the number of children per class, which is negatively correlated with test scores (Angrist and Lavy, 1999). With respect to health, a cohort of smaller size could benefit from more frequent/better access to doctors and hospitals. However, these crowding effects are probably of a less concern in our study. Health outcomes are expected to be more sensitive to mothers' characteristics than to other external factors, especially at birth. So, the situation is very different when compared to studies considering human capital formation: educational outcomes are much more affected by public expenditures.

Overall, the different channels reviewed in this section foretell that abortion legalization should positively affect the outcomes of children born immediately after the lift of the ban compared to children born before the lift. Next, we turn to our data in an attempt to assess the magnitude of the causal link between abortion legalization and children's outcomes in Romania.

\section{Data and descriptive statistics}

\subsection{The Romanian context}

In 1966, Romania abruptly shifted from one of the most liberal abortion policies in the world to a restrictive and conservative policy that made abortion and family planning illegal. ${ }^{8}$ More exactly, the 1966 decree stipulated that abortion was allowed only for women who already

\footnotetext{
${ }^{8}$ According to Berelson (1979), in 1965 there were 408 abortions per 100 live births in Romania.
} 
had four or more children, for women over the age of 45 whose lives were jeopardized by the pregnancy, and for women whose pregnancy resulted from rape or incest. The policy had an immediate success in raising the fertility rate from 1.9 to 3.7 children per woman in one year (Figure 1). The sharp increase was followed by a steady decrease until 1985. ${ }^{9}$ This decline was mainly due to a massive increase in illegal abortions (Kligman, 1998). Abortion stayed illegal until December 1989, when Ceausescu and his regime were removed from power.

\section{Insert Figure 1 here}

As shown in Figure 1, the repeal of the ban on abortion and family planning was followed by an instant decline in the fertility rate, basically due to abortions. In 1990, Romania reached the highest rate of induced abortion in the world: 200 per 1,000 women aged 15-44, a number seven times higher than in the US (Serbanescu et al., 1995). ${ }^{10}$ However, one possible threat to our identification strategy could be that the drop in fertility starting in 1990 is due to a decline in demand for children caused by the transition period and not by the abortion legalization (see also Pop-Eleches, 2009).

To investigate this issue, we first compare the demographic situation in Romania with that in Bulgaria and Hungary, two countries that were also part of the Eastern Bloc until 1989. In these two countries, we do not observe the same downward trend immediately starting in 1990. The decreasing slope is more gradual, and the two curves are very similar only after 1992, as shown in Figure 1. ${ }^{11}$ Another possible threat is that the drop in fertility might be explained by the repeal of different pronatalist policies introduced during the communist era. However, no major changes in the monthly child allowances or maternity leave policies took place immediately after the fall of communism (see World Bank Report, 1992 and PopEleches, 2010, for a more exhaustive discussion).

In Figure 2, we show the number of monthly births in 1989-1991 based on the Romanian natality files. We observe a huge drop in fertility starting roughly six months after abortion was legalized (see also Pop-Eleches, 2009). This six-month lag was expected. Since abortion

\footnotetext{
${ }^{9}$ In 1985, Ceausescu reinforced the decree by raising the number of required children per woman to five (Greenwell, 2003).

${ }^{10}$ Note also the huge number of over 1 million induced abortions in 1990.

${ }^{11}$ Additional evidence is provided by Pop-Eleches (2010) who compares Romanian to its neighboring Moldova, and does not find similar patterns in fertility rates. Moldova is an appropriate comparison since the majority of the population is ethnically Romanian. Also, in Moldova, abortion was not banned before 1989, so any changes after 1989 are basically induced by the transition process. The pattern observed in Moldova is pretty similar to that of other transition countries.
} 
was legalized in late December 1989 and since under the new abortion policy an abortion is allowed only during the first trimester, we expect lower monthly births rates after June 1990.

\section{Insert Figure 2 here}

\subsection{Data}

To study the anthropometric outcomes, we use the first two waves (1994-95 and 1995-96) of the Romanian Integrated Household Survey (RIHS), which is a Living Standards Measurement Study (LSMS) survey administrated by the Romanian National Commission for Statistics (INSE) in cooperation with the Ministry of Labor and Social Protection and with the technical assistance of the World Bank. These are the first Romanian household representative surveys that, in addition to standard socio-economic characteristics, include information on fertility history as well as anthropometric information for children.

It is from these two waves of the survey that we can uncover the information on the cohorts born in July of 1989 and onward, since the questions about anthropometric outcomes were collected for all children 0-60 months of age at the time of the survey. All in all, we have information on almost 5,000 children 0-60 months of age. However, our main cohorts of interest comprise children born in 1989, 1990, and 1991, respectively. More specifically, in the empirical analysis, we consider two different subsamples: July 1989-June $1991(1,875$ observations) and January 1990-December 1991 (1,994 observations).

Our two main outcomes of interest are birth weight and low birth weight. We choose to consider two definitions for low birth weight: the conventional definition which relies on a threshold of $2.5 \mathrm{~kg}$, and also a slightly higher threshold of $3 \mathrm{~kg}$. We choose to proceed in this way as only $4 \%$ of our sample was below the $2.5 \mathrm{~kg}$ limit, compared to $22.6 \%$ when we use the $3 \mathrm{~kg}$ cut-off point. ${ }^{12}$ According to the RIHS, the mean birth weight of the children born July 1989-June 1991 is $3.229 \mathrm{~kg}$, with a standard deviation of 0.439 . Further descriptive statistics are reported in Table 1.

\section{Insert Table 1}

The mean age of the children under consideration is around 50 months and $47 \%$ of the children are girls. Concerning the mother's characteristics, the average age at birth is 24.4 years. About $34 \%$ have finished primary education, $61 \%$ have attended secondary school, and only $5 \%$ have a tertiary education. Ninety percent are ethnically Romanian, $3 \%$ are Roma, and

\footnotetext{
${ }^{12}$ For a similar approach, see for instance Lindeboom et al. (2009).
} 
$7 \%$ are classified as "other" (Hungarian, Germans, etc.). One important issue at this point is to understand how the lift of the ban has changed the composition of families that carried pregnancies to term.

As already explained, we expect the lift of the ban to influence children born in July 1990 or later. We therefore start by checking whether the repeal of the abortion ban had any effect on the composition of families having children one year after this cutoff (July 1990-June 1991) compared to one year before (July 1989-June 1990). From Table 1, we first observe that mothers' age at birth decreased by more than half of year after July 1990, i.e., older women were more likely to benefit from the lift of the ban. Also, we notice that the abortion legalization mainly influenced households from more disadvantaged backgrounds since women with only primary education were less likely to give birth once the abortion and other contraceptive methods were legalized. ${ }^{13}$ These results are in line with Pop-Eleches (2009), who finds a similar composition effect using a sample of the 2002 census.

\section{Empirical strategy}

In what follows, we present our methodology and empirical specifications. Let us start by considering a simple before-after strategy. More exactly, we consider children born July 1989-June 1991, i.e., children within a reasonably short time span before and after July 1990 (when the policy came into effect). We define a treatment dummy $T$, which equals 1 if the child $i$ is born July 1989-June 1990 and 0 if the child $i$ is born July 1990-June 1991. The impact of the policy change is captured by the coefficient $\alpha_{1}$ from the following model:

$$
y_{i}=\alpha_{0}+\alpha_{1} T_{i}+\varepsilon_{i}
$$

where $y_{i}$ represents an outcome of interest (birth weight, low birth weight or z-scores) for a child $i$. This estimation strategy is equivalent to the calculation of a simple difference between the outcomes when $T=1$ and $T=0$. At this stage, it should be noted that our coefficient of interest $\alpha_{1}$ is expected to pick up the overall impact of the abortion legalization on children's health outcomes at birth: both the composition effect and the unwantedness effect.

\footnotetext{
${ }^{13}$ We also find that out-of-wedlock/divorced mothers (at the time of the survey) are less likely to give birth once the abortion ban is lifted. However, we do not include this covariate in our analysis due to potentially high endogeneity concerns.
} 
In an attempt to control for the composition effect, we further add a set of observable controls into (1):

$$
y_{i}=\beta_{0}+\beta_{1} T_{i}+\beta_{2} X_{i}+\varepsilon_{i}
$$

where $y_{i}$ and $T_{i}$ are defined as above, and $X_{i}$ is a set of child and family background variables. More exactly, we control for the mother's education (three dummies), mother's ethnicity (three dummies), mother's age at birth, an urban dummy for the child's place of birth, a dummy for the sex of the child, 8 region of birth dummies, and a survey wave indicator. ${ }^{14} \mathrm{We}$ also include two household specific controls, measured at the time of the survey: the number of durables goods in the household (such as TV, radio, car, computer, etc) and the log of household consumption, which is presumably a better measure of long-term resource availability than income. ${ }^{15}$ After we control for the composition effect in (2), $\beta_{1}$ captures the unwantedness effect. ${ }^{16}$

To assess the impact of the lift on the abortion ban, we further rely on a difference-indifference strategy. The intuition is as follows. Suppose that the lift of the ban indeed has a positive effect on children's health at birth. Then, in 1990, one should observe an increase in health among children born during the $2^{\text {nd }}$ semester (July-December) if compared to those born during the $1^{\text {st }}$ semester (January-June). However a large number of empirical studies have highlighted that health outcomes are not orthogonal to calendar effects. This finding holds both in developed countries like the US (van Hanswijck de Jonge et al., 2003) and Japan (Tanaka et al., 2007) and in transition and developing countries like Poland (Koscinski et al., 2004) and India (Lokshin and Radyakin, 2009).

\footnotetext{
${ }^{14}$ One potential concern is related to the possible endogeneity of mother's education, since this variable is measured at the time of the survey and not at the time of birth. Alternatively, we include a dummy for the mother's education that equals 1 if she has more than primary education. That is because most Romanian women finish primary education before age 15 and do not have children by that time, and, therefore, the endogeneity issue is of a less concern (see also Pop-Eleches, 2010). The results (available upon request) are very similar.

${ }^{15}$ Since these household controls are potentially more endogenous as they are measured at the time of the survey, we have also used different specifications in our estimation: 1) we try to take into account only the durables available during the year the child was born (since we know the year the household acquired each of these durables), 2) we control for other household specific variables such as number of rooms per occupant, square feet per occupant, homeownership, type of heating, type of lighting in the house (electric or not), conditional on that they have not moved during the last 3-4 years. Our results are robust to these specifications.

${ }^{16}$ Some other economic or demographic factors at the county/regional level may have been useful to consider, e.g., poverty rate, unemployment rate, an inequality index. However, we could not find any information by region/county and month for the years 1989 or 1990, so we are not able to include these controls in our regressions. Some information on the county level (but not on a monthly base) becomes available starting with 1990. Also, remember that the official unemployment rate in Romania during the Ceausescu regime was zero percent, so many of these numbers would be unreliable.
} 
Yet, if such correlations between a child's health outcomes and semester of birth do exist, then we should observe a similar tendency for those born during the $2^{\text {nd }}$ semester (if compared to those born during the $1^{\text {st }}$ semester) in 1990 and in 1991. Or, put differently, if the abortion legalization had a significant effect, the difference between 1991 and 1990 in health outcomes for children born January-June should be positive and significant, while we do not expect any significant difference in health between children born July-December 1991 and those born July-December 1990.

Our main identification assumption is that 1990 and 1991 are similar years, and they are indeed. No major reforms took place in the provision of maternity and child benefits in the first three years following the fall of communism (see World Bank, 2002). Additionally, different demographic and economic indicators (e.g., number of beds in hospitals, number of marriages, births attended by skilled health personnel, GDP per capita, Gini income) remained pretty stable during 1990 and 1991 (UNICEF TransMonee, 2008; Statistics Romania). ${ }^{17}$

Our difference-in-difference is obtained from the following model:

$$
y_{i}=\gamma_{0}+\gamma_{1} T_{i}+\gamma_{2} D_{90, i}+\gamma_{3}\left(T_{i} \times D_{90, i}\right)+\varepsilon_{i}
$$

where $y$ is defined as before, $T$ is equal to one when the child was born during the $2^{\text {nd }}$ semester (and 0 otherwise), and $D_{90}$ is a dummy that takes the value 1 if the child was born in 1990 and 0 if born in 1991. It captures factors that would have changed $y$ even in the absence of the policy. The parameter of interest is $\gamma_{3}$, the coefficient associated to the interaction between $T$ and $D_{90}$. The crossed term equals one for the children born in the $2^{\text {nd }}$ semester of 1990 and captures the effect of the policy on the treatment group.

If there are indeed positive consequences of the lift of the abortion ban, then we expect to find a positive value for $\gamma_{3}$. In other words, the difference in $y$ between children born during the $2^{\text {nd }}$ semester and children born during the $1^{\text {st }}$ semester should be significantly higher in 1990 than in 1991. Conversely, in the absence of the abortion effect, the difference in outcomes between

\footnotetext{
17 One possible threat to this identification strategy could be related to the emotional changes related to the political transformations. Recent evidence suggests that prenatal stress may influence both the duration of the pregnancy and fetal maturation and thus increase the risk of adverse outcomes at birth (Camacho, 2008). However, we believe that this is not of a serious concern in our estimations. First, as we explained, most of the economic/demographic indicators were pretty stable in 1990 and 1991. Secondly most of the Romanians felt joy, and optimism in December 1989 (Gallagher, 2005). However, we cannot exclude the fact that happiness and optimism may, in turn, affect how women perceive their unplanned or unwanted pregnancy at the time of conception.
} 
children born during the $2^{\text {nd }}$ and the $1^{\text {st }}$ semester should be similar in 1990 and 1991 and $\gamma_{3}$ will remain insignificant.

As with the before-after estimates, we also incorporate some control variables to pick up the composition effect of women giving birth:

$$
y_{i}=\delta_{0}+\delta_{1} T_{i}+\delta_{2} D_{90, i}+\delta_{3}\left(T_{i} \times D_{90, i}\right)+\delta_{4} X_{i}+\varepsilon_{i}
$$

When estimating (4), we have also investigated the possibility of different returns to the exogenous covariates in 1990 and 1991, respectively, by adding interaction terms of the form $X_{i} \times D_{90, i}{ }^{18}$

\section{The impact of abortion legalization on children's health outcomes}

\subsection{Birth weight and low birth weight}

Table 2 reports our results from estimating equations (1) and (2) on birth weight (panel A), low birth weight on the basis of the traditional cutoff point $(<2.5 \mathrm{~kg}$ ) (panel B), and low birth weight with a higher threshold $(<3 \mathrm{~kg})$ (panel C). We start by showing the estimates of $\alpha_{1}$ without controls (in Columns $a$ ) and $\beta_{1}$ with family background variables (in Columns $b$ ).

\section{Insert Table 2 here}

In panel A, we start by considering the birth weight outcome. Although the pattern of our estimates is positive, the estimates reveal no significant effects in the baseline specification in Column (1a) or after we control for the composition effect in Column (1b). We consider separately girls (Columns 2a, 2b) and boys (Columns 3a, 3b) and also urban (Columns 4a, 4b) and rural (Columns 5a, 5b). ${ }^{19}$ The pattern is still positive, but our estimates do not turn out significant. Next, in panel B, we consider the low birth weight outcome $(<2.5 \mathrm{~kg})$. The pattern of our estimates is now negative (as expected), but none of the estimates is significant. Finally, in panel $\mathrm{C}$, we consider a higher threshold for birth at weight $(<3 \mathrm{~kg})$. The overall impact of the abortion legalization appears to be positive. Both in Columns (1a) and (1b), the estimates are negative and significant at the $10 \%$ level, suggesting that children born after the

\footnotetext{
${ }^{18}$ We have also estimated models with a set of month of birth dummies (or a polynomial of the month of birth) of the child. Our results (available upon request) are very robust to the inclusion of a linear monthly trend and month of birth dummies.

${ }^{19}$ There is abundant evidence that especially in some developing countries, households generally favor boys. At the same time, there are usually significant differences between urban and rural areas (see Haddad et al., 1997, for a survey).
} 
abortion ban was lifted had a 3.7\% lower likelihood of having a low birth weight. Additionally, our coefficient of interest is negative and significant at the $10 \%$ level when we consider the boys as well as the urban sample.

Table 3 presents our main results for the health at birth outcomes using equations (3) and (4). More exactly, we start by showing the following coefficients: the coefficient on the treatment dummy variable $\gamma_{1}$, i.e., whether the child is born during the $2^{\text {nd }}$ semester; $\gamma_{2}$, the year 1990 indicator; and our main coefficient of interest $\gamma_{3}$, i.e., the crossed term between the treatment and year indicator dummy. The crossed term is expected to capture the overall impact of the change in the abortion legislation on the newborns' health outcomes. For each outcome, we report estimates from our specification (3) in Columns $a$ and (4) in Columns $b$.

\section{Insert Table 3 here}

In panels $\mathrm{A}$ and $\mathrm{B}$, we consider the birth weight outcome and the low birth weight $(<2.5 \mathrm{~kg})$. Although the pattern of the interaction term is again as expected, it is never significant. In panel $\mathrm{C}$, we present the low birth weight outcome $(<3 \mathrm{~kg})$. Now, the overall impact of the abortion legalization is positive and substantial. In Columns (1a) and (1b), the estimate for $\gamma_{3}$ is negative and significant at the 5\% level, suggesting that children born after the abortion ban was lifted had a lower likelihood of suffering from low birth weight. The results have a similar pattern when we consider only the urban area, with our coefficient of interest still significant at the $5 \%$ level but of even larger magnitude. Also, in Columns (2b) and (3b), we observe that girls had a lower likelihood of low birth weight if born immediately after the abortion legalization. One possible explanation is that girls are more likely to be affected by unhealthy prenatal care than boys. In particular, there are studies showing that the negative effect of maternal smoking during pregnancy on birth weight is greater in newborn girls than in newborn boys (Hermanussen et al., 2006).

\subsubsection{Further discussions and robustness check}

Let us attempt to assess the relevance of our results. A first issue is to know whether we are right in assuming that the decline in fertility relates to change in abortion policy (and not by some improvement in the socio-economic conditions within the country immediately after the fall of communism) as discussed in Section 3.1. Thus, we decide to perform a simple falsification exercise to confirm that this is indeed the case.

More specifically, we replicate our empirical strategy on health at birth outcomes using children born in 1991 and 1992 (1,854 observations), the $2^{\text {nd }}$ semester being our treatment 
group. ${ }^{20}$ Of course, since there is no change in abortion availability during these years, we expect the cross product between the 1991 year dummy and the $2^{\text {nd }}$ semester dummy to be insignificant (i.e., for low birth weight $(<3 \mathrm{~kg})$ ), unless we pick up something else (for instance some other socio-economic transformations). When we apply our difference-in-difference estimation strategy, the crossed term is equal to -0.063 ( $\mathrm{t}=-1.55)$ for birth weight with no controls and $-0.033(\mathrm{t}=-0.82)$ with controls. Even though the estimates are still not significant, we observe that the sign has reversed compared to Table 3, panel A. Concerning the probability of observing the birth weight below a given threshold, the crossed terms are negative and insignificant at the 5 percent level: $-0.012(\mathrm{t}=-1.68)$ without covariates and 0.018 ( $\mathrm{t}=-1.20)$ with covariates for low birth weight $(<2.5 \mathrm{~kg}), 0.056(\mathrm{t}=1.33)$ without covariates and $0.036(\mathrm{t}=0.86)$ with covariates for low birth weight $(<3 \mathrm{~kg})$. The fact that these crossed terms are never significant at the 5 percent level is consistent with our assumption that the drop in fertility after June 1990 is due to changes in access to abortion. ${ }^{21}$

Next, we discuss our insignificant estimates respectively for birth weight and low birth weight $(<2.5 \mathrm{~kg})$. In particular, the lack of a significant effect of the abortion legalization on these health outcomes could be due to our relatively small sample size. Drawing on Monte Carlo simulation, we study next the power of a 0.05 test against the null hypothesis that there is no effect for various sample sizes.

Consider for instance the case of birth weight. Using the estimated coefficients described in Table 2 and drawing residuals from the corresponding normal distribution, we construct a set of simulated values for birth weight and estimate a linear regression expressing birth weight as a function of a treatment dummy. ${ }^{22}$ We then check the significance level of the coefficient associated to the treatment dummy. We repeat the procedure for sample sizes ranging from 250 to 10,000 (with an increment of 250) and consider 2,500 replications for the simulations. According to our results, the probability of having a statistically significant effect (at the 5\% level) of the treatment is less than $60 \%$ for birth weight and about $20 \%$ for very low birth weight $(<2.5 \mathrm{~kg})$ when the simulated sample comprises 10,000 observations. This pattern holds because we have a very low coefficient of the treatment dummy for both child health outcomes. The lack of effect of changes in abortion policy on usual child health outcomes

\footnotetext{
${ }^{20}$ While we only present the difference-in-difference strategy, the results (available upon request) attained using a before and after strategy are very similar. Additionally, we have also considered another falsification exercise using children born in 1992 and 1993. As in the 1991-1992 case, the interaction terms are never significant.

${ }^{21}$ We have also performed a falsification exercise using the 1992-1993 years and reach similar conclusions: the crossed term measure the possible effect of a (fictitious) change in abortion policy is never significant

${ }^{22}$ The treatment values are obtained by rounding draws from a uniform distribution.
} 
(birth weight, birth weight less than $2.5 \mathrm{~kg}$ ) is an important result with respect to the existing literature on socio-economic consequences stemming from changes in abortion policy.

Furthermore, we try to see whether our estimates, after controlling for changes in composition of women more likely to carry pregnancies to term, are consistent with the observed yearly aggregate data. ${ }^{23}$ Figure 3 shows a stable pattern immediately before and after 1990 on the low birth weight outcome $(<2.5 \mathrm{~kg})$, while we observe a slight increase after the lift of abortion ban for the low birth weight $(<3 \mathrm{~kg})$ and the birth weight. These aggregate trends suggest that, except for the infant mortality, the lift of the abortion ban did not drastically change the health outcomes at birth. However, the comparison between our results when using household data and the aggregate statistics suggest that taking into account the changes in the composition of women giving birth is very important. Overall, our results from household data where we also take into account the changes in the composition effect are consistent with the aggregate data and our findings do not seem to be driven by our relatively small sample size.

\section{Insert Figure 3 here}

At the same time, it is important to keep in mind that our empirical analysis probably underestimates the impact of the abortion legalization on birth outcomes. Indeed from Figure 3 it is clear that the abortion legalization had also decreased infant mortality. These children were probably the weakest in terms of birth weight. Consequently, we should interpret our results as children's outcomes given that the child survived (i.e., survived birth or the first year of life). As a consequence, our conditional estimates (given the child survived) provide a lower bound of the effect of the lift of the abortion ban. Unfortunately, there is no information in the data that could allow us to correct for the possible underlying selection bias. ${ }^{24}$

\subsection{Anthropometric weight-for-height and height-for-age z-scores}

We now present additional evidence on the two most commonly used nutritional outcomes measured at the time of the survey: 1) weight-for-height which is an indicator of wasting and reflects the current malnutrition status relative to height, and 2) height-for-age, which is an indicator of stunting due to chronic malnutrition attributed to long-term protein deficiency

\footnotetext{
${ }^{23}$ The only information available at Statistics Romania is aggregate yearly data on low birth weight $(<2.5 \mathrm{~kg}$ and $<3 \mathrm{~kg}$ ) outcomes (monthly data would have been preferable).

${ }^{24}$ Moreover, our estimates may be contaminated by omitted characteristics of the mothers' prenatal behavior (e.g., smoking, drinking). However, we expect this to affect similarly mother's characteristics immediately before and after 1990 .
} 
and/or low food intake for long periods of time, reflects not only current status but also past health and nutritional investment. ${ }^{25}$

When turning to the data, we standardize our anthropometric measures using a reference of well-nourished children (see WHO, 2006). The reference population is used to calculate the anthropometric indices that can be expressed in terms of z-scores. ${ }^{26}$ Before presenting our main results, we briefly discuss some descriptive statistics. ${ }^{27}$ First, the average weight-forheight is 0.655 standard deviations above the median of the reference population; second, the height-for-age indicator is more than one standard deviation below the median of the reference population, indicating that chronic malnutrition is important among Romanian children.

\section{Insert Table 4 here}

We use a similar estimation strategy as for the birth weight outcome. Table 4 presents the regression results for equations (1) and (2) using the before-after strategy, while Table 5 reports results from estimating equations (3) and (4) using the difference-in-difference strategy. Additionally, in all of our regressions, we control for the child's age in months. ${ }^{28}$ In panel A, we consider the weight-for-height z-scores and in panel B the height-for-age $\mathrm{z}$ scores. The estimates in Tables 4 and 5 reveal no significant effects for the two considered nutritional outcomes. ${ }^{29}$

\section{Insert Table 5 here}

We need to be cautious about inferring strong conclusions since there are several potential threats to our identification strategy when we turn to the anthropometric z-scores. One potential concern is related to the issue of measurement error. It is generally argued that children's anthropometric status such as current weight and height/length are difficult to measure. According to the RIHS survey manual provided by the World Bank, the current weight and height information was collected during the $2^{\text {nd }}$ compulsory visit at the household,

\footnotetext{
${ }^{25}$ The weight-for-height and height-for-age indicators may or may not move together. For instance, a child with chronic malnutrition may not necessarily suffer from acute malnutrition (Victoria, 1991).

${ }^{26}$ More exactly, the z-scores are calculated for a child's weight (or height), given age and gender, by subtracting the median weight (or height) in the reference population and dividing by the standard deviation of the reference population. The main idea is that children under normal conditions grow in similar patterns, and therefore any deficiency in growth could be attributed to an unfavorable situation.

${ }^{27}$ We have already excluded 78 observations with extreme z-scores. "Extreme" usually means a z-score above 6 (in absolute value) for height-for-age and above 5 (in absolute value) for weight-for-height (WHO, 2006).

${ }^{28}$ The results, however, are very similar when we do not. Also, our results (available upon request) are very robust to the inclusion of a linear monthly trend.

${ }^{29}$ In addition, we considered low (below -2 SD) weight-for-height (or wasting) and height-for-age (or stunting), but the results do not turn out significant.
} 
while during the $1^{\text {st }}$ visit mothers were asked to bring their children to the territorial dispensaries, where current height and weight were documented.

We cannot assess the magnitude of the possible under/over measurement reporting. If parents would over-report the weight and/or height of their weakest children (and if the weakest children are those born under the restrictive abortion regime) and correctly report the measures of their other children, we would probably find, on average, no significant differences between the two groups. It is important to stress that for birth weight, the possible measurement error issue is reduced to a minimum since birth weight is usually based on the child's medical certificate..$^{30}$

Another potential concern with the z-score outcomes is that the nutritional status of very young children may change rapidly with age regardless of the existence of an external shock. Of a special concern, it is the height-for-age z-score which is a stock or long-term indicator, resulting from low growth due to protein deficiency for longer periods of time, and reflects not only current but also past health and nutritional investment. Thus, older children may accumulate a larger deficit resulting in lower height for age if compared to younger children (see Bundervoet et al., 2009; Martorell and Habicht, 1986).

The nutritional literature recommends comparing children within certain age intervals in order to avoid capturing the pattern of malnutrition which changes with age. Waterlow et al. (1977) suggests the following age intervals: 1) highly recommended: 0-2.99 months, 3-5.99 months, 6-8.99 months, 9-11.99 months, 1-1.99 years, 2-2.99 years, 3-3.99 years, 4-4.99 years; 2) recommended: 0-5.99 months, 6-11.99 months, 1-1.99 years, 2-3.99 years, 4-5.99 years; 3) permissible: 0-11.99 months, 1-1.99 years, and 2-5.99 years. We compare children about 49 months old (in the before-after estimation strategy) and children about 45 months old (in the difference-in-difference strategy), while the average age difference between the treated and the control group is less than 12 months. So, any possible bias due to aging is reduced to minimum. This provides some evidence that any relationship that we may find is not due to a differential age pattern. ${ }^{31}$

\footnotetext{
${ }^{30}$ In Romania, when mothers leave the hospital/clinic after giving birth, they are automatically issued a medical certificate for the child ("Certificat medical constatator al nascutului viu") stating, among other information, birth weight. This certificate must be presented when registering the child in the national registry. One additional concern may be related to the number of children born at home. However, less than $1 \%$ of the children in our sample were born at home.

${ }^{31}$ However, in our analysis, we have also controlled for potential age effects by controlling for the child's age in months. Additionally, another potential concern may be that children are measured in two different survey years. The results based on only one survey wave (1994-1995, to capture children born in 1989) do not vary.
} 


\section{Abandoned children}

So far, we have only considered the effect of abortion legalization on outcomes of noninstitutionalized children. However, this leads to an incomplete picture since the institutionalized children were probably the true "unwanted" children. These are children living in an institution or residential care for more than ten children, without parents, in which care is provided by some professional personnel (Browne, 2009).

The high number of institutionalized children was, arguably, one of the most shocking outcomes of the Romanian abortion ban and lack of family planning. "The State wanted them, the State should raise them" became an accepted norm under the Ceausescu regime, claimed by families when leaving their children in maternity wards, hospitals, or directly in institutions. In this section, we attempt to understand the effect of abortion legalization by focusing on the undocumented category of institutionalized children. For this purpose, we make use of a unique census data that covers all Romanian institutionalized children in 1997.32

The backgrounds of these children are poorly documented, in particular due to very limited information about their biological families (Carter, 2005). Our data provides some useful information, e.g., birth year and month, whether the child has any family contact, and whether the child entered the current institution from his/her family or from another institution. Next, we distinguish between two main categories of children: 1) abandoned children, defined here as children who have living parents, but who have no contact with them and/or are declared legally abandoned and 2) temporarily institutionalized children, defined here as institutionalized children who stayed in contact with their families. ${ }^{33}$ The latter group included children temporarily institutionalized by their families due to poor economic conditions or some other social motive, but also children who needed special care. ${ }^{34}$

Institutionalization may be seen as a way for very poor families to invest in their children's human capital by temporarily institutionalizing their children. This clearly sets up a selection

\footnotetext{
${ }^{32}$ This is the first data available since these children were not included in any official statistics.

33 The juvenile delinquents and children in correctional facilities are excluded from our analysis.

${ }^{34}$ Children who needed special care were children with deficiencies (such as mental problems, dystrophies, or deafness), malformations or HIV/AIDS positive. These children were almost never enrolled in regular schools or kindergartens (Mitrut, 2008).
} 
problem that prevents us from identifying a clear-cut link with the issue of unwantedness. Thus, in what follows, we only concentrate on the abandoned children and do not consider the case of temporarily institutionalized children. The proportion of abandoned children accounted for $32 \%$ (or 30,300 children) of all institutionalized children according to the 1997 census.

\section{Insert Figure 4 here}

Figure 4 presents the number of abandoned children born in 1989-1991, by month of birth. We observe an abrupt drop in the number of abandoned children starting roughly six months after the lift of the ban, similar to Figure 2. However, the relevant outcome here is the number of abandoned children relative to the cohort size at birth, by month and year of birth. We make use of the Romanian 1992 census to calculate these proportions by region of birth. Additionally, we also construct a measure for child abandonment at birth using the information on whether the abandoned child entered the current institution directly from their families or from another institution. ${ }^{35}$

Figure 5 depicts the abandoned children per 10,000 live births, by month and year of birth. It suggests that the lift of the ban had an immediate effect on child abandonment. In particular, we observe a sharp drop in the number of abandoned children per 10,000 live births starting July 1990. However, starting with 1991, we observe a slight increase in the number of abandoned children relative to the total live births. In what follows, we try to understand the causal impact of the lift of the ban on child abandonment per 10,000 live births by month, year and region of birth using similar specifications to those described in Section $4 .{ }^{36}$

\section{Insert Figure 5 here}

In Table 6, we present the results from a before-after strategy. In panel A, Columns (1a) - (1c) we consider children born January - December 1990, i.e., six months before and after July 1990. As a robustness check, in panel B, Columns (1a) - (1c) we also consider children born

\footnotetext{
${ }^{35}$ The institutional setting specified that abandoned children of three years of age or younger lived in leagane (nurseries) or hospitals. It was only after the age of three that children were transferred to case de copii (children's home), camine spital (hospital placement centers), or gradinite speciale (special kindergartens) (Mitrut, 2008). Most of the children were usually abandoned immediately after birth in hospitals or maternity wards.

${ }^{36}$ We use regional variation in child abandonment and fertility history. According to Romanian National Statistics, the Romanian territory is organized into 8 regions. Alternatively, we could have used the variation at the county level ( 42 counties), but we have many observations with no child abandonment. Additionally, the fact that we do not know whether the abandoned children were institutionalized in the same county in which they were born may introduce some measurement error. Using regions instead of counties will reduce any possible measurement errors. However, we have tried all our specifications using the county of birth variation. The results, available upon request, are very similar to those obtained when using regional variation.
} 
July 1989-June 1991, one year before and after July 1990. The treatment dummy equals 1 for children born after July 1990 and 0 otherwise. Additionally, in Columns (2a) - (2c), panels A and B we try to capture the effect of the abortion legalization on child unwantedness at birth.

\section{Insert Table 6 here}

As expected, the overall pattern of our estimates is negative, suggesting that indeed the lift of the abortion ban has decreased the number of abandoned children in the total live births. However, these results require some further discussions. In panel A, column (1a), the immediate effect, with no other controls, seems to be negative but not significant. In column (1b), we include the region of birth dummies to control for important time invariant heterogeneity across regions and our treatment dummy turns out significant at the $10 \%$ level. ${ }^{37}$ In particular, it seems that the immediate impact of abortion legalization on child abandonment was of about 4 abandoned children per 10,000 live births. This effect, even though statistically significant, is arguably quite low in magnitude. Finally, although in Figure 4 we do not observe any trend 6 months before and after July 1990, in column (1c) we include a linear time trend in month of birth. The treatment dummy is still negative and significant but, not surprisingly, the magnitude of the coefficient (and the standard errors) is now twice as big compared to column (1b). This occurs because of the correlation between the treatment and the calendar month variable.

This overall pattern is consistent when we look at abandonment at birth, in columns (2a) (2c): the treatment variable is now significant at the $5 \%$ level. As robustness test, in panel B of Table 6, we consider children born July 1989 - June 1991. Our results are comparable to those in panel A, but the negative coefficient for the treatment dummy turns significant only once the linear trend is introduced as explanatory variable.

Finally, in Table 7, we consider a difference-in-difference strategy for children born January 1990 - December 1991. Our key coefficient, the interaction term between the treatment and being born after 1990, is negative and significant at the $1 \%$ level in all our specifications. We conclude that abandonment was reduced during the first six months after the lift of abortion ban, a finding consistent with a 'wantedness' effect.

\section{Insert Table 7 here}

\footnotetext{
37 According to Romanian National Statistics, there is no information on some economic or demographic characteristics by region and month for the years 1989 or 1990, so we are not able to include other controls in our regressions.
} 
However, our results have to be interpreted with care due to several reasons. First, they are probably only a lower bound of the true effects given that we do not know the death rate among children in the state run institutions and we have no information about adoption. Secondly, we lack information on individual characteristics of women abandoning their children (before or immediately after 1990), meaning that we cannot control for any possible change over time in the composition of women abandoning their children.

\section{Conclusion}

In this paper, we explore how the lift of the Romanian abortion ban in December 1989, when dictator Ceausescu was killed and his regime was removed from power, affected Romanian children's health at birth and during early childhood (at age 4 and 5) and the impact of the lift of the ban on child abandonment.

We conduct our empirical analysis on children's outcomes at birth and during early childhood using the first representative Romanian surveys that includes information on anthropometric measures. Using a before-after and a difference-in-difference estimation strategy, we find that our main coefficient of interest has the expected sign, but they do not turn out statistically significant. The only significant result is that children born after abortion became legal have a $3.7 \%$ lower likelihood of having a low birth weight $(<3 \mathrm{~kg})$ than children born prior to the policy change.

Our results thus suggest that the lift of abortion ban has at best a very limited impact on child health. Interestingly, these findings are very different from those found in Romania when the focus is on education or labor market outcomes (see Pop-Eleches, 2006, 2009). One possible concern is our relatively small sample, but calculations indicate that statistic significance would not be reached for birth weight and very low birth weight even with a much larger sample size.

Our findings are consistent with (at least) two possible explanations. The first one has to do with emotional changes and in particular with the fact that even though the children born just before July 1990 (as compared to those born immediately after July 1990) were unplanned or unwanted at the time of conception, after the collapse of the communist regime women were more positive (see Gallagher, 2005), so they could have developed a mechanism of late (4 month or later) prenatal care. The second explanation is related to the intergenerational transmission of health at birth. Currie and Moretti (2007) show that there is a strong 
intergenerational correlation in the birth weight of mothers and children, so that interventions meant to break this cycle are likely to be noticed only in the next generation's health at birth.

Our paper is also the first study that attempts to assess a causal relationship between abortion and child abandonment by using a unique data set covering all institutionalized children in Romania in 1997. We first notice that the lift of the abortion ban in December 1989 led to an immediate reduction in the number of abandoned children. Next, we use the variation in fertility and child abandonment at the regional level and find that the immediate impact of abortion legalization on child abandonment was of about 4 abandoned children per 10,000 live births. This effect is robust across different specifications but, even though statistically significant, is arguably quite low in magnitude. However, as we do not have information about infant mortality, the true (unobserved) effect of the lift in abortion ban could be in reality much larger.

Our paper has shown that abortion legalization in Romania had positive consequences such as decreasing the number of abandoned children. However, it would be worthwhile to further understand the consequences of access to family planning on child abandonment. Nevertheless, as they stand, our results suggest that the lack of access to family planning may have unexpected, life lasting consequences, such as institutionalization in the form of abandonment of the unwanted or unplanned children.

\section{References}

Almond, D., Currie, J., (2010), "Human Capital Development Before Age Five", NBER working paper 15827 .

Angrist, J.D., Evans, W., (1999), "Schooling and Labor Market Consequences of the 1970 State Abortion Reforms", in Polachek S.W., ed., Research in Labor Economics, vol. 18, pp. 75-113.

Angrist, J.D., Lavy, V., (2006), "Using Maimonides' Rule To Estimate The Effect Of Class Size On Scholastic Achievement”, Quarterly Journal of Economics, vol. 114, pp. 533-575.

Becker, G., (1981), A Treatise on the Family, Cambridge, MA: Harvard University Press.

Becker, G., Lewis, G., (1973),'On the Interaction between the Quantity and Quality of Children", Journal of Political Economy, vol. 81, pp. S279-88.

Bitler, M., Zavodny, M., (2002), "Child Abuse and Abortion Availability", American Economic Review, vol. 92, pp. 363-367.

Berelson, B., (1979), “Romania's 1966 Anti-Abortion Decree: The Demographic Experience of the First Decade", Population Studies, vol.33, 209-22. 
Browne, K., (2009), "The Risk of Harm to Young Children in Institutional Care", Save the Children, mimeo, UK.

Bundervoet, T., Vewimp, P., Akresh, R., (2009),'Health and Civil War in Rural Burundi”, Journal of Human Resources, vol. 44, pp. 536-62.

Camacho, A. (2008), "Stress and Birth Weight: Evidence from Terrorist Attacks", American Economic Review, Vol. 98, No. 2, pp. 511-15.

Carter, R. (2005). Family Matters: A study of institutional childcare in Central and Eastern Europe and the Former Soviet Union, London: Everychild.

Case, A., Fertig, A., Paxson, C., (2005), "The Lasting Impact of Childhood Health and Circumstance", Journal of Health Economics, vol. 24, pp. 365-389.

Case, A., Lubotsky, D., Paxson, C., (2002), "Economic Status and Health in Childhood: The Origins of the Gradient", American Economic Review, vol. 92, pp. 1308-1334.

Charles, K., Stephens, M., (2006), "Abortion Legalization and Adolescent Substance Use", Journal of Law and Economics, vol. 49, pp.481-505.

Currie, J., Moretti, E., (2007), "Biology as Destiny? Short- and Long-Run Determinants of Intergenerational Transmission of Birth Weight," Journal of Labor Economics, vol. 25, pp. 231-264.

Donohue, J., Levitt, S., (2001), “The Impact of Legalized Abortion on Crime", Quarterly Journal of Economics, vol. 116, pp. 379-420.

Donohue, J., Levitt, S., (2004), "Further Evidence that Legalized Abortion Lowered Crime: A Reply to Joyce", Journal of Human Resources, vol. 39, pp. 29-49.

Foote, C., Goetz, C., (2008), "The Impact of Legalized Abortion on Crime: Comment," Quarterly Journal of Economics, vol. 123, pp. 407-423.

Fraser, A.M., Brockert, J.E., Ward, R.H., (1995), “Association of Young Maternal Age with Adverse Reproductive Outcomes", New England Journal of Medicine, vol. 332, pp. 1113-17.

Gallagher, T., (2005), Theft of a Nation: Romania since Communism, Hurst \&Co., UK.

Greenwell, K., (2003), "The Effects of Child Welfare Reform on Levels of Child Abandonment and Deinstitutionalization in Romania, 1987-2000", mimeo, University of Texas Austin.

Grossman, M., Joyce, T., (1990), "Unobservables, Pregnancy Resolutions, and Birth Weight Production Functions in New York City", Journal of Political Economy, vol. 98, pp. 9831007.

Grossman, M., Jacobowitz, S., (1981), "Variations in Infant Mortality Rates Among Counties of the United States: The Role of Public Policies and Programs", Demography, vol.18, pp. 695-713.

Gruber, J., Levine P., Staiger, D., (1999), "Abortion Legalization and Child Living Circumstances: Who is the Marginal Child?", Quarterly Journal of Economics, vol. 114, pp. 263-91. 
Haddad, L., Hoddinott, J. and Alderman, H. (1997), Intra-household Resource Allocation in Developing Countries: Model, Methods, and Policy, Johns Hopkins University Press, Baltimore.

van Hanswijck de Jonge, L., Waller, G., Stetter, N., (2003) "Ethnicity modifies seasonal variation in birth weight and weight gain of infants." Journal of Nutrition, vol. 133, pp.141518 .

M. Hermanussen, U. Wittwer-Backofen, C. Fusch and V. Hesse (2006), "Sex-specific differences in birth weight due to maternal smoking during pregnancy", European Journal of Pediatrics, vol.165, pp.757-761.

Johnson, D. (2000). 'Medical and developmental sequelae of early childhood institutionalization in international adoptees from Romania and the Russian Federation' in C. Nelson (Ed.), The Effects of Early Adversity on Neurobehavioral Development. Mahwah, NJ: Lawrence Erlbaum Associates.

Jolly, M., Sebire, N., Harris, J., Robinson S., Regan, L.,(2000),” The risks associated with pregnancy in women aged 35 years or older", Human Reproduction, vol. 15, pp. 2433-37.

Kligman, G., (1998), The Politics of Duplicity: Controlling Reproduction in Ceausescu's Romania, Los Angeles: University of California Press.

Koscinski, K., Krenz-Niedbala, M., Kozlowska-Rajewicz A. (2004) "Month-of-birth effect on height and weight in Polish rural children", American Journal of Human Biology, vol. 16, pp. $31-42$.

Lindeboom, M., Llena-Nozal, A., van der Klaauw, B., (2009),"Parental Education and Child Health: Evidence From a Schooling Reform", Journal of Health Economics, vol. 28, 109-31.

Lokshin, M., Radyakin, S., (2009), "Month of Birth and Children's Health in India", mimeo, World Bank, Policy Research Working Paper 4813.

Martorell, R., Habicht, J-P., (1986), "Growth in Early Childhood in Developing Countries", In Human Growth: A Comprehensive Treatise, ed. Falkner, F., Tanner, J. Plenum Press. New York.

Maclean, K., (2003), "The Impact of Institutionalization on Child Development", Development and Psychopathology, 15, pp. 853-884.

Mitrut, A., (2008), "Behind Closed Doors. School Enrollment of Romanian Institutionalized Children", mimeo, Department of Economics, Uppsala University.

Nelson, C., Zeneah, C., Fox, N., Marshall, P., Smyke, A., Guthrie, D., (2007), "Cognitive Recovery in Socially Deprived Young Children: The Bucharest early Intervention Project", Science, 318.

Pop-Eleches, C., (2006), "The Impact of an Abortion Ban on Socioeconomic Outcomes of Children: Evidence from Romania”, Journal of Political Economy, vol. 114, pp. 744-773.

Pop-Eleches, C., (2009), "Abortion and child cognitive outcomes", mimeo, University of Columbia.

Pop-Eleches, C., (2010), "The Supply of Birth Control Methods, Education and Fertility: Evidence from Romania”, Journal of Human Resources, vol. 45, pp. 971-997. 
Rosenzweig, M., Schultz, P., (1983), "Estimating a Household Production Function: Heterogeneity, the Demand for Health Inputs, and Their Effects on Birth Weight", Journal of Political Economy, vol. 91, pp. 723-46.

Serbanescu, F., Morris, L., Stupp, P., Stanescu, A., (1995), "The Impact of Recent Policy Changes on Fertility, Abortion, and Contraceptives in Romania", Studies in Family Planning, vol. 26, pp.76-87.

Smith, J.P., (1998), "Socioeconomic Status and Health", American Economic Review, vol. 88, pp. 192-96.

Smith, J.P., (2009), "The Impact of Childhood Health on Adult Labor Market Outcomes", Review of Economics and Statistics, vol. 91, pp. 478-489.

Tanaka, H., Sei, M., Binh, T., Munakata, H., Yuasa, K., Nakahori, Y., (2007) "Correlation of month and season of birth with height, weight and degree of obesity of rural Japanese children" Journal of Medical Investigation, vol.54, pp. 133-139.

UNICEF (1997) and National Committee for Child Protection, Government of Romania. "Situatia Copilului si a familiei in Romania".

UNICEF TransMONEE (2008), www.unicef-irc.org//databases/transmonee.

Victoria, C.G., (1991), "The Association between Wasting and Stunting: An International Perspective", Journal of Nutrition, vol. 5, pp. 1105-10.

Waterlow, J.C., Ruzina, R., Keller, W., Lane, J.M., Nichaman, M. Z.,Tanner, J.M., (1977), "The Presentation and Use of Height and Weight Data for Comparing the Nutritional Status of Groups of Children Under the Age of 10 years", Bulletin of the World Health Organization, vol. 55, pp. 489-98.

WHO, (2006), WHO Multicenter Growth Reference Study Group. WHO Child Growth Standards: Length/height-for-age, weight-for-age, weight-for-length, weight-for-height and body mass index-for-age: Methods and development. Geneva: World Health Organization.

World Bank, (1992). Romania: Human Resources and the Transition to a Market Economy. World Bank: Washington, DC.

Zamfir, E., (1997), "Social Services for Children at Risk: the Impact on the Quality of Life", vol. 42, pp. 41-76. 
Fig. 1 - Total Fertility Rate in Romania vs. other transition countries, 1962-2002

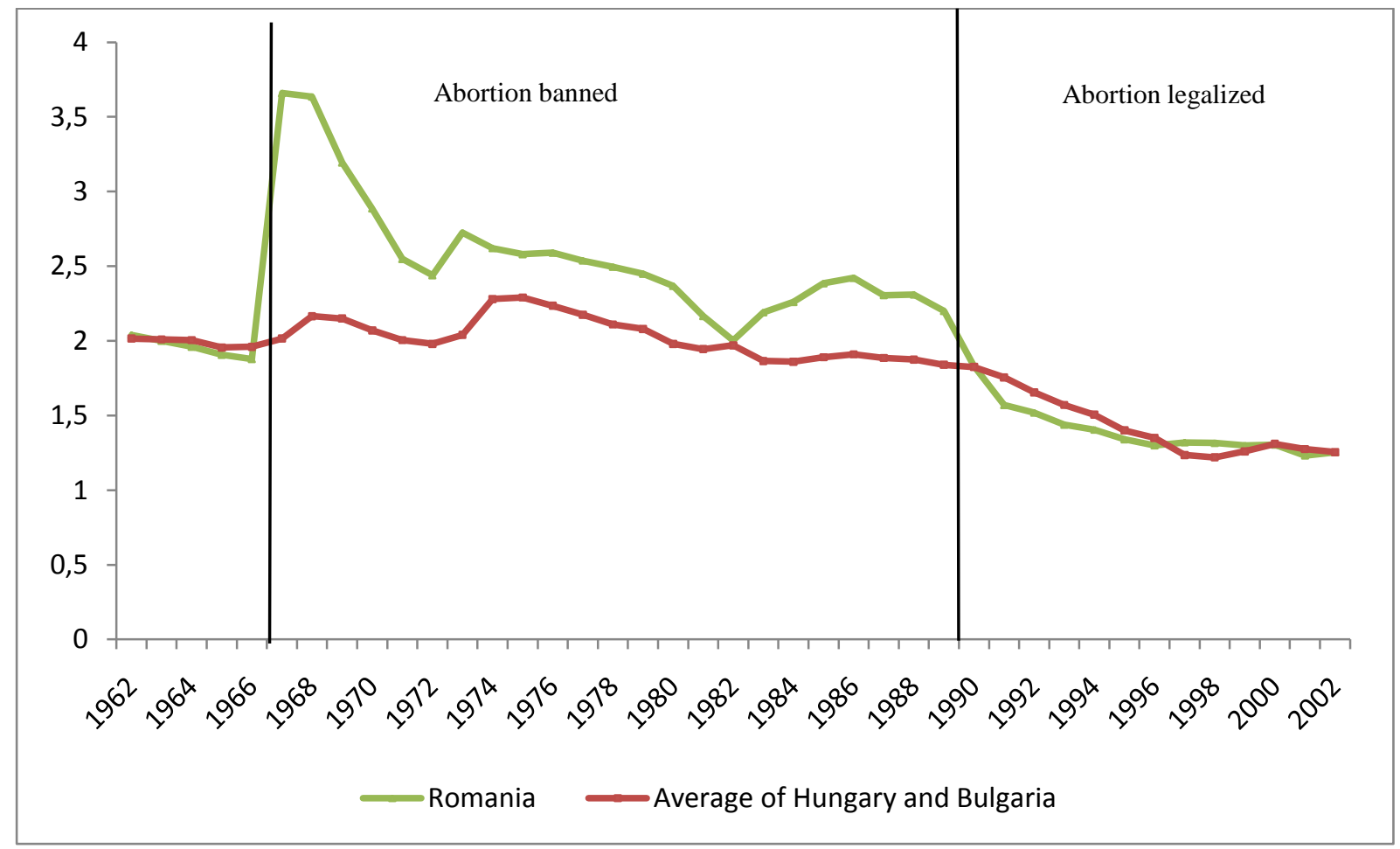

Source: UN (2002).

Fig. 2 - Cohort Size at Birth, by Month of Birth, July 1989- June 1991

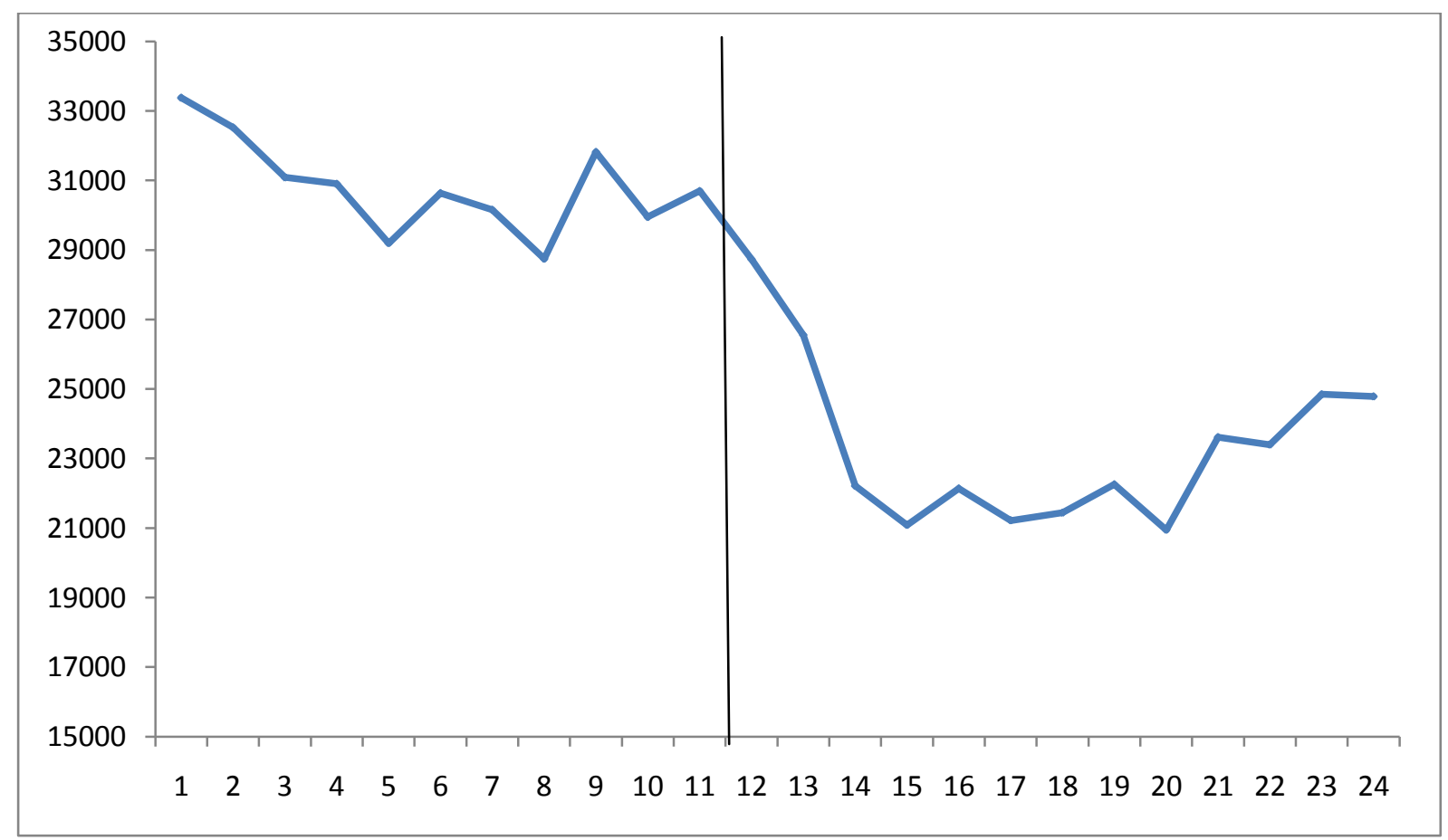

Notes: July 1989 = Month 1. Source: Romanian Demographic Yearbook, 2005, INSE, Romania. 
Fig. 3 - Aggregate Yearly Average: Low Birth Weight $(<2.5 \mathrm{~kg}$ and $<3 \mathrm{~kg})$, Very Low Birth Weight $(<1.5 \mathrm{~kg})$, Infant Mortality and Birth Weight $(\mathrm{kg})$

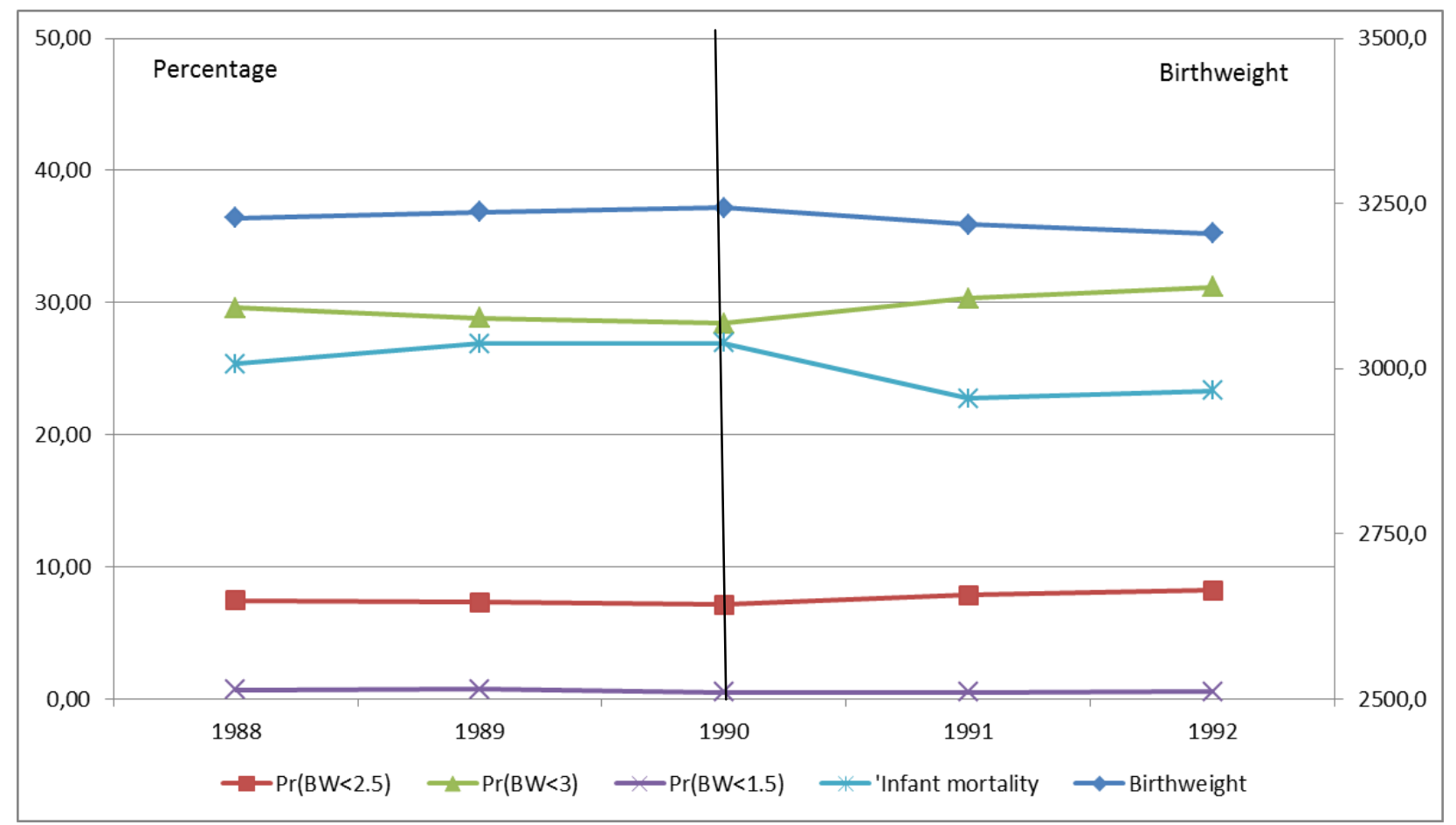

Source: Romanian Demographic Yearbook (2006), Statistics Romania. 
Fig. 4 - Abandoned Children: cohort size at birth, by month and year of birth, July 1989 - June 1991

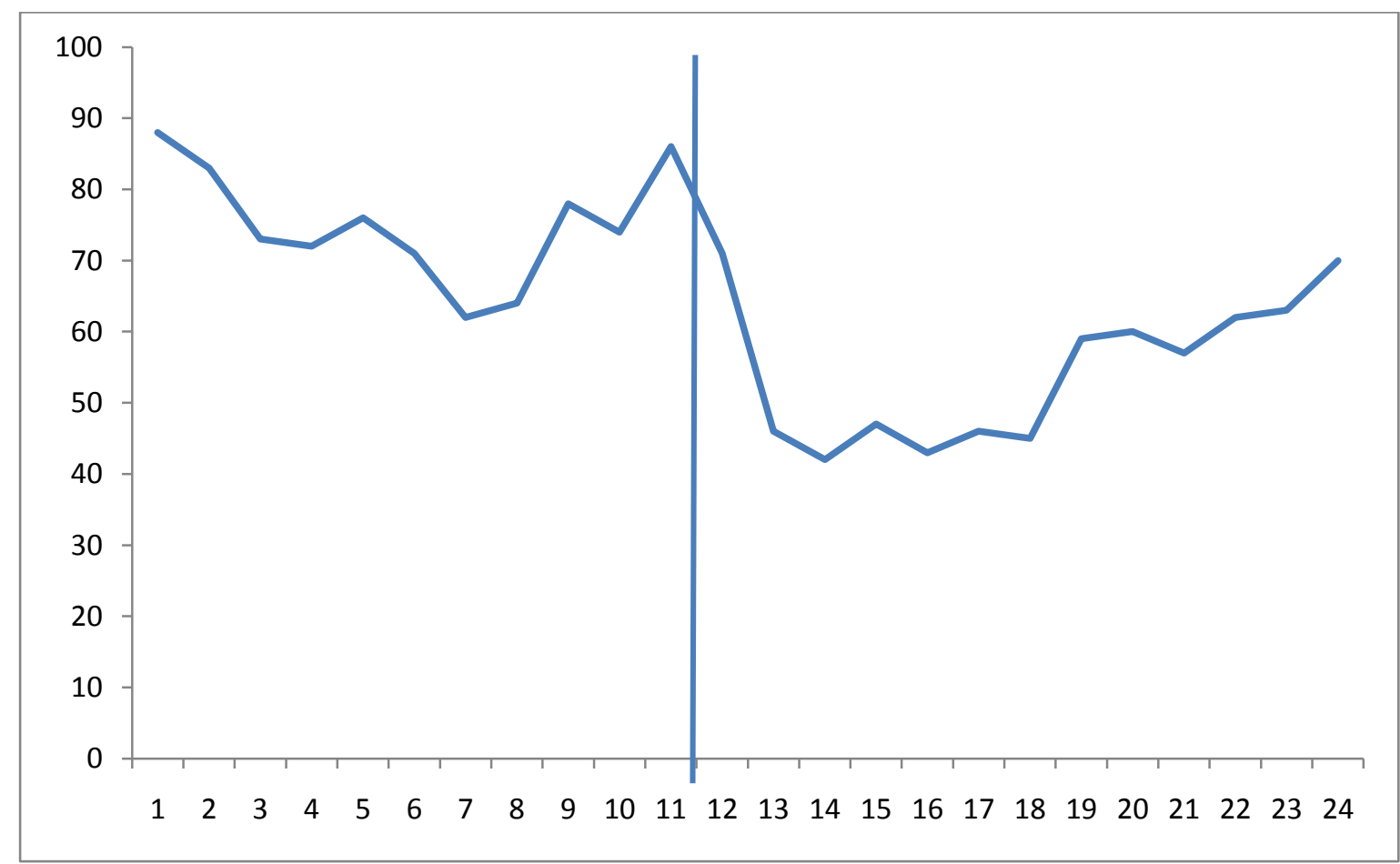

Notes: July 1989 = Month 1. Source: the 1997 Romanian Census of the Institutionalized Children, INSE, Romania.

Fig. 5 - Abandoned Children per 10,000 live births, by month and year of birth, July 1989 - June 1991

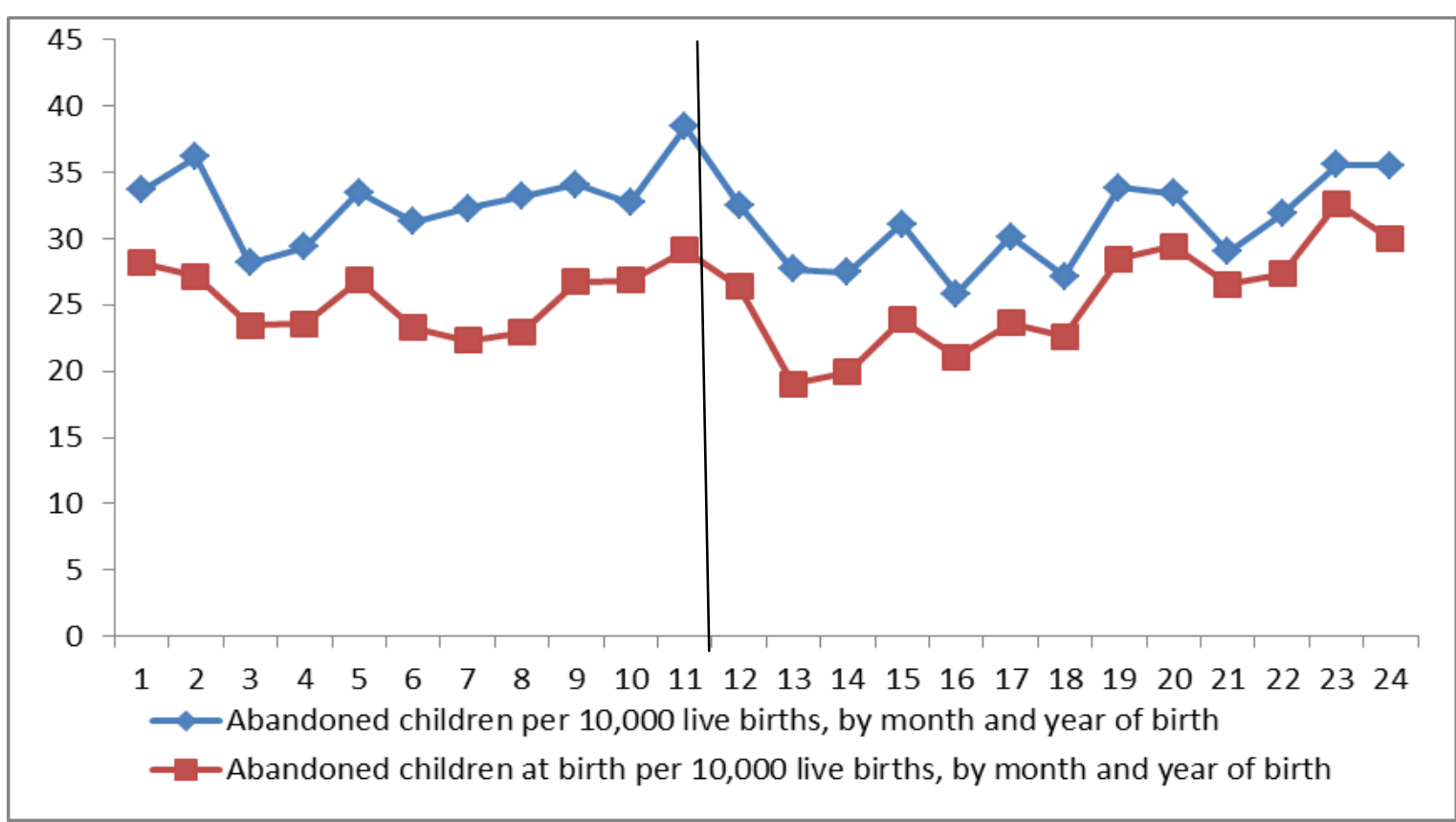

Notes: July 1989 = Month 1. Source: the 1997 Romanian Census of the Institutionalized Children and the 1992 Romanian Census, INSE, Romania 
Table 1. Descriptive statistics of the sample (including comparison of means)

\begin{tabular}{|c|c|c|c|c|c|}
\hline Variables & $\begin{array}{c}\text { Control group } \\
\text { (July 1989-- } \\
\text { June 1990) }\end{array}$ & $\begin{array}{c}\text { Treatment group } \\
\text { (July 1990- June } \\
\text { 1991) }\end{array}$ & $\begin{array}{l}\text { Difference: } \\
\text { treatment-control }\end{array}$ & Mean & $\begin{array}{l}\text { Standard } \\
\text { deviation }\end{array}$ \\
\hline \multicolumn{6}{|l|}{ Mother's characteristics } \\
\hline Mother's age at birth & 24.842 & 24.208 & $-0.634^{* * *}$ & 24.414 & 5.390 \\
\hline \multicolumn{6}{|l|}{ Mother's education } \\
\hline Primary & 0.361 & 0.312 & $-0.048^{* *}$ & 0.336 & 0.472 \\
\hline Secondary & 0.599 & 0.642 & $0.043^{*}$ & 0.621 & 0.485 \\
\hline Tertiary & 0.040 & 0.045 & -0.004 & 0.042 & 0.202 \\
\hline \multicolumn{6}{|l|}{ Mother's ethnicity: } \\
\hline Romanian & 0.907 & 0.906 & -0.001 & 0.907 & 0.290 \\
\hline Rooma/Gypsy & 0.071 & 0.073 & -0.002 & 0.073 & 0.259 \\
\hline Other & 0.020 & 0.019 & 0.001 & 0.020 & 0.141 \\
\hline \multicolumn{6}{|l|}{ Household economic conditions } \\
\hline Log of total consumption & 12.224 & 12.210 & -0.014 & 12.217 & 0.766 \\
\hline Number of durables & 5.356 & 5.333 & -0.023 & 5.345 & 2.941 \\
\hline \multicolumn{6}{|l|}{ Child's characteristics } \\
\hline Gender: girl & 0.470 & 0.471 & 0.001 & 0.470 & 0.499 \\
\hline Child's age (in months) & 54.561 & 44.704 & $-9.857^{* * *}$ & 49.546 & 6.506 \\
\hline Place of birth: rural & 0.481 & 0.484 & 0.003 & 0.483 & 0.500 \\
\hline Height (in centimeters) & 101.833 & 96.385 & $-5.448 * * *$ & 99.061 & 7.105 \\
\hline Weight (in kilograms) & 16.894 & 15.392 & $-1.502 * * *$ & 16.130 & 2.388 \\
\hline Birth weight (in kilograms) & 3.219 & 3.239 & 0.019 & 3.229 & 0.439 \\
\hline
\end{tabular}

Notes: Significance levels are $1 \%\left({ }^{* * * *}\right), 5 \%\left({ }^{* * *}\right)$ and $10 \%\left({ }^{*}\right)$. Total number of observations is 1,875 .

Source: Authors' calculations using the 1994-95 and 1995-96 RIHS. 
Table 2. Before-after estimates of the effect of the 1989 abortion legalization on children birth weight (July 1989 - June1991)

\begin{tabular}{|c|c|c|c|c|c|c|c|c|c|c|}
\hline & \multicolumn{2}{|c|}{ All } & \multicolumn{2}{|c|}{ Girls } & \multicolumn{2}{|c|}{ Boys } & \multicolumn{2}{|c|}{ Urban } & \multicolumn{2}{|c|}{ Rural } \\
\hline \multirow{3}{*}{ Born after July 1990} & (1a) & (1b) & $(2 a)$ & $(2 b)$ & $(3 a)$ & $(3 b)$ & $(4 a)$ & $(4 b)$ & $(5 a)$ & $(5 b)$ \\
\hline & 0.020 & 0.023 & -0.011 & -0.003 & 0.047 & 0.045 & 0.026 & 0.034 & 0.013 & 0.013 \\
\hline & $(0.020)$ & $(0.020)$ & $(0.028)$ & $(0.029)$ & $(0.029)$ & $(0.029)$ & $(0.029)$ & $(0.029)$ & $(0.028)$ & $(0.028)$ \\
\hline Background controls & NO & YES & NO & YES & NO & YES & NO & YES & NO & YES \\
\hline Number of observations & 1875 & 1875 & 882 & 882 & 993 & 993 & 970 & 970 & 905 & 905 \\
\hline $\mathrm{R}^{2}$ & 0.001 & 0.046 & 0.001 & 0.047 & 0.003 & 0.059 & 0.001 & 0.049 & 0.001 & 0.056 \\
\hline \multicolumn{11}{|c|}{ B. Low birth weight $(<2.5 \mathrm{~kg})$} \\
\hline & \multicolumn{2}{|c|}{ All } & \multicolumn{2}{|c|}{ Girls } & \multicolumn{2}{|c|}{ Boys } & \multicolumn{2}{|c|}{ Urban } & \multicolumn{2}{|c|}{ Rural } \\
\hline \multirow{3}{*}{ Born after July 1990} & (1a) & $(1 \mathrm{~b})$ & $(2 a)$ & $(2 b)$ & $(3 a)$ & $(3 b)$ & $(4 a)$ & $(4 \mathrm{~b})$ & $(5 \mathrm{a})$ & $(5 b)$ \\
\hline & -0.005 & -0.008 & -0.013 & -0.012 & 0.003 & -0.002 & -0.007 & -0.008 & -0.002 & -0.002 \\
\hline & $(0.009)$ & $(0.008)$ & $(0.014)$ & $(0.012)$ & $(0.013)$ & $(0.011)$ & $(0.013)$ & $(0.012)$ & $(0.014)$ & $(0.012)$ \\
\hline Background controls & NO & YES & NO & YES & NO & YES & NO & YES & NO & YES \\
\hline Number of observations & 1875 & 1875 & 882 & 882 & 993 & 933 & 970 & 970 & 905 & 905 \\
\hline Pseudo- $\mathrm{R}^{2}$ & 0.001 & 0.057 & 0.003 & 0.051 & 0.001 & 0.093 & 0.001 & 0.060 & 0.001 & 0.099 \\
\hline \multicolumn{11}{|c|}{ C. Low birth weight $(<3 \mathrm{~kg})$} \\
\hline & \multicolumn{2}{|c|}{ All } & \multicolumn{2}{|c|}{ Girls } & \multicolumn{2}{|c|}{ Boys } & \multicolumn{2}{|c|}{ Urban } & \multicolumn{2}{|c|}{ Rural } \\
\hline \multirow{3}{*}{ Born after July 1990} & (1a) & $(1 b)$ & (2a) & $(2 \mathrm{~b})$ & $(3 a)$ & (3b) & $(4 a)$ & (4b) & $(5 a)$ & $(5 b)$ \\
\hline & $-0.034^{*}$ & $-0.037^{*}$ & -0.018 & -0.022 & $-0.047^{*}$ & $-0.047^{*}$ & -0.037 & $-0.045^{*}$ & -0.030 & -0.030 \\
\hline & $(0.019)$ & $(0.020)$ & $(0.029)$ & $(0.030)$ & $(0.026)$ & $(0.026)$ & $(0.027)$ & $(0.027)$ & $(0.028)$ & $(0.029)$ \\
\hline Background controls & NO & YES & NO & YES & NO & YES & NO & YES & NO & YES \\
\hline Number of observations & 1875 & 1875 & 882 & 882 & 993 & 993 & 970 & 970 & 905 & 905 \\
\hline Pseudo- $\mathrm{R}^{2}$ & 0.002 & 0.023 & 0.001 & 0.032 & 0.003 & 0.036 & 0.002 & 0.034 & 0.001 & 0.024 \\
\hline
\end{tabular}

Notes: Panel A presents the results of OLS regressions. Panel B presents the results of Probit regressions. For continuous variables, the coefficient represents the marginal effect of variables evaluated at their mean. For dummy variables, the coefficients capture the effect of switching the value from 0 to 1 . Robust standard errors are shown in parentheses, while significance levels are $1 \%\left({ }^{* * *}\right), 5 \%\left({ }^{* *}\right)$ and $10 \%\left({ }^{*}\right)$. Background controls include an indicator for the child's gender, two indicator variables for mother's education, two indicator variables for mother's ethnicity, a rural dummy for the place of birth of the child, 8 regions of birth dummies, log of total consumption, number of durables, number of children in the household and a survey year indicator.

Source: Authors' calculations using the 1994-95 and 1995-96 RIHS. 
Table 3. Difference-in-difference estimates of the effect of the 1989 abortion legalization on children birth weight (using the 1990 and 1991 birth cohorts)

\begin{tabular}{|c|c|c|c|c|c|c|c|c|c|c|}
\hline & \multicolumn{2}{|c|}{ All } & \multicolumn{2}{|c|}{ Girls } & \multicolumn{2}{|c|}{ Boys } & \multicolumn{2}{|c|}{ Urban } & \multicolumn{2}{|c|}{ Rural } \\
\hline & (1a) & (1b) & $(2 a)$ & $(2 b)$ & $(3 a)$ & $(3 b)$ & $(4 a)$ & (4b) & $(5 a)$ & $(5 b)$ \\
\hline Born second semester & $\begin{array}{l}-0.050^{*} \\
(0.028)\end{array}$ & $\begin{array}{l}-0.041 \\
(0.029)\end{array}$ & $\begin{array}{l}-0.057 \\
(0.036)\end{array}$ & $\begin{array}{l}-0.054 \\
(0.037)\end{array}$ & $\begin{array}{l}-0.029 \\
(0.043)\end{array}$ & $\begin{array}{l}-0.027 \\
(0.044)\end{array}$ & $\begin{array}{l}-0.079^{*} \\
(0.042)\end{array}$ & $\begin{array}{l}-0.076^{*} \\
(0.042)\end{array}$ & $\begin{array}{l}-0.018 \\
(0.039)\end{array}$ & $\begin{array}{l}-0.017 \\
(0.039)\end{array}$ \\
\hline Born in 1990 & $\begin{array}{l}-0.033 \\
(0.027)\end{array}$ & $\begin{array}{l}-0.041 \\
(0.027)\end{array}$ & $\begin{array}{l}0.005 \\
(0.037)\end{array}$ & $\begin{array}{l}-0.005 \\
(0.038)\end{array}$ & $\begin{array}{l}-0.066^{*} \\
(0.040)\end{array}$ & $\begin{array}{l}-0.067^{*} \\
(0.039)\end{array}$ & $\begin{array}{l}-0.041 \\
(0.039)\end{array}$ & $\begin{array}{l}-0.056 \\
(0.039)\end{array}$ & $\begin{array}{l}-0.025 \\
(0.038)\end{array}$ & $\begin{array}{l}-0.030 \\
(0.038)\end{array}$ \\
\hline Born $2^{\text {nd }}$ semester * born in 1990 & $\begin{array}{l}0.048 \\
(0.039)\end{array}$ & $\begin{array}{l}0.043 \\
(0.039)\end{array}$ & $\begin{array}{l}0.006 \\
(0.053)\end{array}$ & $\begin{array}{l}0.011 \\
(0.054)\end{array}$ & $\begin{array}{l}0.072 \\
(0.057)\end{array}$ & $\begin{array}{l}0.072 \\
(0.057)\end{array}$ & $\begin{array}{l}0.075 \\
(0.057)\end{array}$ & $\begin{array}{l}0.081 \\
(0.056)\end{array}$ & $\begin{array}{l}0.020 \\
(0.054)\end{array}$ & $\begin{array}{l}0.024 \\
(0.054)\end{array}$ \\
\hline Background controls & NO & YES & NO & YES & NO & YES & $\mathrm{NO}$ & YES & NO & YES \\
\hline $\begin{array}{l}\text { Number of observations } \\
\mathrm{R}^{2}\end{array}$ & $\begin{array}{l}1994 \\
0.002\end{array}$ & $\begin{array}{r}1994 \\
0.039\end{array}$ & $\begin{array}{c}978 \\
0.004\end{array}$ & $\begin{array}{c}978 \\
0.034\end{array}$ & $\begin{array}{l}1016 \\
0.003\end{array}$ & $\begin{array}{l}1016 \\
0.051\end{array}$ & $\begin{array}{l}1019 \\
0.004\end{array}$ & $\begin{array}{c}1019 \\
0.046\end{array}$ & $\begin{array}{c}975 \\
0.001\end{array}$ & $\begin{array}{c}975 \\
0.046\end{array}$ \\
\hline \multicolumn{11}{|c|}{ B. Low birth weight $(<2.5 \mathrm{~kg})$} \\
\hline & \multicolumn{2}{|c|}{ All } & \multicolumn{2}{|c|}{ Girls } & \multicolumn{2}{|c|}{ Boys } & \multicolumn{2}{|c|}{ Urban } & \multicolumn{2}{|c|}{ Rural } \\
\hline Born second semester & $\begin{array}{c}(1 \mathrm{a}) \\
-0.009 \\
(0.014)\end{array}$ & $\begin{array}{c}(1 b) \\
-0.006 \\
(0.012)\end{array}$ & $\begin{array}{c}(2 \mathrm{a}) \\
0.014 \\
(0.020)\end{array}$ & $\begin{array}{c}(2 b) \\
0.008 \\
(0.018)\end{array}$ & $\begin{array}{c}(3 \mathrm{a}) \\
-0.030 \\
(0.019)\end{array}$ & $\begin{array}{c}(3 b) \\
-0.018 \\
(0.015)\end{array}$ & $\begin{array}{c}(4 a) \\
-0.008 \\
(0.020)\end{array}$ & $\begin{array}{c}(4 b) \\
-0.003 \\
(0.016)\end{array}$ & $\begin{array}{c}(5 a) \\
-0.010 \\
(0.019)\end{array}$ & $\begin{array}{c}(5 b) \\
-0.007 \\
(0.016)\end{array}$ \\
\hline Born in 1990 & $\begin{array}{c}0.009 \\
(0.012)\end{array}$ & $\begin{array}{c}0.011 \\
(0.011)\end{array}$ & $\begin{array}{c}0.021 \\
(0.018)\end{array}$ & $\begin{array}{c}0.019 \\
(0.017)\end{array}$ & $\begin{array}{c}0.002 \\
(0.016)\end{array}$ & $\begin{array}{c}0.002 \\
(0.012)\end{array}$ & $\begin{array}{c}0.017 \\
(0.016)\end{array}$ & $\begin{array}{c}0.017 \\
(0.014)\end{array}$ & $\begin{array}{c}0.001 \\
(0.017)\end{array}$ & $\begin{array}{l}-0.002 \\
(0.015)\end{array}$ \\
\hline Born $2^{\text {nd }}$ semester ${ }^{*}$ born in 1990 & $\begin{array}{c}-0.004 \\
(0.018)\end{array}$ & $\begin{array}{l}-0.005 \\
(0.016)\end{array}$ & $\begin{array}{l}-0.020 \\
(0.020)\end{array}$ & $\begin{array}{l}-0.015 \\
(0.019)\end{array}$ & $\begin{array}{c}0.016 \\
(0.031)\end{array}$ & $\begin{array}{c}0.006 \\
(0.022)\end{array}$ & $\begin{array}{l}-0.002 \\
(0.025)\end{array}$ & $\begin{array}{c}-0.001 \\
(0.021)\end{array}$ & $\begin{array}{l}-0.006 \\
(0.025)\end{array}$ & $\begin{array}{c}-0.006 \\
(0.020)\end{array}$ \\
\hline Background controls & NO & YES & NO & YES & NO & YES & NO & YES & NO & YES \\
\hline Number of observations & 1994 & 1994 & 978 & 978 & 1016 & 1016 & 1019 & 1019 & 975 & 975 \\
\hline Pseudo $\mathrm{R}^{2}$ & 0.003 & 0.045 & 0.004 & 0.045 & 0.009 & 0.098 & 0.007 & 0.068 & 0.003 & 0.092 \\
\hline \multicolumn{11}{|c|}{ C. Low birth weight $(<3 \mathrm{~kg})$} \\
\hline & \multicolumn{2}{|c|}{ All } & \multicolumn{2}{|c|}{ Girls } & \multicolumn{2}{|c|}{ Boys } & \multicolumn{2}{|c|}{ Urban } & \multicolumn{2}{|c|}{ Rural } \\
\hline & (1a) & (1b) & $(2 a)$ & $(2 b)$ & $(3 a)$ & $(3 b)$ & $(4 a)$ & (4b) & $(5 a)$ & $(5 b)$ \\
\hline Born second semester & $\begin{array}{c}0.055^{*} \\
(0.028)\end{array}$ & $\begin{array}{c}0.046 \\
(0.028)\end{array}$ & $\begin{array}{l}0.099^{* *} \\
(0.042)\end{array}$ & $\begin{array}{l}0.102^{* *} \\
(0.042)\end{array}$ & $\begin{array}{l}-0.001 \\
(0.038)\end{array}$ & $\begin{array}{l}-0.002 \\
(0.038)\end{array}$ & $\begin{array}{l}0.071^{*} \\
(0.040)\end{array}$ & $\begin{array}{c}0.067^{*} \\
(0.039)\end{array}$ & $\begin{array}{c}0.038 \\
(0.040)\end{array}$ & $\begin{array}{c}0.030 \\
(0.040)\end{array}$ \\
\hline Born $2^{\text {nd }}$ semester ${ }^{*}$ born in 1990 & $\begin{array}{l}-0.080^{* * *} \\
(0.034)\end{array}$ & $\begin{array}{l}-0.074^{* * *} \\
(0.034)\end{array}$ & $\begin{array}{l}-0.087^{*} \\
(0.051)\end{array}$ & $\begin{array}{l}-0.092^{*} \\
(0.051)\end{array}$ & $\begin{array}{c}-0.061 \\
(0.046)\end{array}$ & $\begin{array}{c}-0.060 \\
(0.046)\end{array}$ & $\begin{array}{l}-0.106^{* * *} \\
(0.045)\end{array}$ & $\begin{array}{l}-0.109^{* * *} \\
(0.044)\end{array}$ & $\begin{array}{c}-0.053 \\
(0.050)\end{array}$ & $\begin{array}{c}-0.049 \\
(0.051)\end{array}$ \\
\hline Background controls & $\mathrm{NO}$ & YES & $\mathrm{NO}$ & YES & NO & YES & $\mathrm{NO}$ & YES & NO & YES \\
\hline Number of observations & 1994 & 1994 & 978 & 978 & 1016 & 1016 & 1019 & 1019 & 975 & 975 \\
\hline Pseudo $\mathrm{R}^{2}$ & 0.003 & 0.023 & 0.005 & 0.027 & 0.004 & 0.030 & 0.004 & 0.034 & 0.002 & 0.024 \\
\hline
\end{tabular}

Notes: Panel A presents the results of OLS regressions. Panel B presents the results of Probit regressions. For continuous variables, the coefficient represents the marginal effect of variables evaluated at their mean. For dummy variables, the coefficients capture the effect of switching the value from 0 to 1 . Robust standard errors are shown in parentheses, while significance levels are $1 \%\left({ }^{* * *}\right), 5 \%\left(^{* *}\right)$ and $10 \%\left(^{*}\right)$. Background controls include an indicator for the child's gender, two indicator variables for mother's education, two indicator variables for mother's ethnicity, a rural dummy for the place of birth of the child, 8 regions of birth dummies, log of total consumption, number of durables, number of children in the household and a survey year indicator.

Source: Authors' calculations using the 1994-95 and 1995-96 RIHS. 
Table 4. Before-after estimates of the effect of the 1989 abortion legalization on children z-scores (July 1989 - June1991) A. Weight-for-height z-score

\begin{tabular}{|c|c|c|c|c|c|c|c|c|c|c|}
\hline & \multicolumn{2}{|c|}{ All } & \multicolumn{2}{|c|}{ Girls } & \multicolumn{2}{|c|}{ Boys } & \multicolumn{2}{|c|}{ Urban } & \multicolumn{2}{|c|}{ Rural } \\
\hline \multirow{3}{*}{ Born after July 1990} & (1a) & (1b) & $(2 a)$ & $(2 b)$ & (3a) & $(3 b)$ & (4a) & $(4 b)$ & (5a) & $(5 b)$ \\
\hline & 0.093 & -0.085 & $0.223^{* *}$ & 0.001 & -0.021 & -0.194 & 0.140 & -0.057 & 0.045 & -0.113 \\
\hline & $(0.072)$ & $(0.122)$ & $(0.101)$ & $(0.165)$ & $(0.101)$ & $(0.179)$ & $(0.098)$ & $(0.174)$ & $(0.104)$ & $(0.172)$ \\
\hline Background controls & NO & YES & NO & YES & $\mathrm{NO}$ & YES & NO & YES & NO & YES \\
\hline Number of observations & 1,875 & 1,875 & 882 & 882 & 993 & 993 & 970 & 970 & 905 & 905 \\
\hline $\mathrm{R}^{2}$ & 0.001 & 0.023 & 0.006 & 0.038 & 0.000 & 0.029 & 0.002 & 0.023 & 0.000 & 0.041 \\
\hline \multicolumn{11}{|c|}{ B. Height-for-age z-score } \\
\hline & \multicolumn{2}{|c|}{ All } & \multicolumn{2}{|c|}{ Girls } & \multicolumn{2}{|c|}{ Boys } & \multicolumn{2}{|c|}{ Urban } & \multicolumn{2}{|c|}{ Rural } \\
\hline \multirow{3}{*}{ Born after July 1990} & (1a) & (1b) & (2a) & (2b) & $(3 a)$ & $(3 b)$ & $(4 a)$ & (4b) & $(5 a)$ & $(5 b)$ \\
\hline & -0.073 & -0.038 & -0.108 & -0.010 & -0.042 & -0.059 & -0.120 & -0.047 & -0.021 & -0.043 \\
\hline & $(0.068)$ & $(0.113)$ & $(0.097)$ & $(0.153)$ & $(0.096)$ & $(0.166)$ & $(0.096)$ & $(0.163)$ & $(0.097)$ & $(0.159)$ \\
\hline Background controls & NO & YES & $\mathrm{NO}$ & YES & $\mathrm{NO}$ & YES & NO & YES & NO & YES \\
\hline Number of observations & 1,875 & 1,875 & 882 & 882 & 993 & 993 & 970 & 970 & 905 & 905 \\
\hline $\mathrm{R}^{2}$ & 0.01 & 0.061 & 0.01 & 0.100 & 0.00 & 0.054 & 0.01 & 0.073 & 0.00 & 0.068 \\
\hline
\end{tabular}

Notes: Panel A and B present the results of OLS regressions. Robust standard errors are shown in parentheses, while significance levels is $1 \%\left({ }^{* * * *}\right), 5 \%\left({ }^{* *}\right)$ and $10 \%\left({ }^{*}\right)$.

Background controls include an indicator for the child's gender, child' age in months, two indicator variables for mother's education, two indicator variables for mother's

ethnicity, a rural dummy for the place of birth of the child, 8 regions of birth dummies, log of total consumption, number of durables, number of children in the household.

Source: Authors' calculations using the 1994-95 RIHS. 
Table 5. Difference-in-difference estimates of the effect of the 1989 abortion legalization on children z-scores (using the 1990 and 1991 birth cohorts)

\begin{tabular}{|c|c|c|c|c|c|c|c|c|c|c|}
\hline & \multicolumn{2}{|c|}{ All } & \multicolumn{2}{|c|}{ Girls } & \multicolumn{2}{|c|}{ Boys } & \multicolumn{2}{|c|}{ Urban } & \multicolumn{2}{|c|}{ Rural } \\
\hline \multirow{3}{*}{ Born second semester } & (1a) & (1b) & $(2 a)$ & $(2 b)$ & $(3 a)$ & $(3 b)$ & $(4 a)$ & $(4 b)$ & $(5 a)$ & $(5 b)$ \\
\hline & 0.012 & $-0.207^{*}$ & -0.075 & -0.224 & 0.118 & -0.188 & -0.110 & $-0.371^{* *}$ & 0.144 & -0.108 \\
\hline & $(0.101)$ & $(0.120)$ & $(0.138)$ & $(0.167)$ & $(0.149)$ & $(0.173)$ & $(0.142)$ & $(0.171)$ & $(0.144)$ & $(0.171)$ \\
\hline \multirow[t]{2}{*}{ Born in 1990} & $-0.161^{*}$ & $0.351^{* * *}$ & $-0.353^{* * *}$ & 0.005 & 0.021 & $0.752^{* * *}$ & $-0.323^{* *}$ & 0.209 & 0.013 & $0.628^{* *}$ \\
\hline & $(0.094)$ & $(0.170)$ & $(0.134)$ & $(0.226)$ & $(0.130)$ & $(0.257)$ & $(0.128)$ & $(0.237)$ & $(0.137)$ & $(0.250)$ \\
\hline \multirow[t]{2}{*}{ Born second semester ${ }^{*}$ born in 1990} & 0.071 & 0.057 & 0.266 & 0.244 & -0.140 & -0.157 & 0.276 & 0.289 & -0.149 & -0.147 \\
\hline & $(0.139)$ & $(0.138)$ & $(0.190)$ & $(0.189)$ & $(0.204)$ & $(0.202)$ & $(0.195)$ & $(0.194)$ & $(0.200)$ & $(0.198)$ \\
\hline Background controls & NO & YES & NO & YES & NO & YES & NO & YES & NO & YES \\
\hline \multirow{5}{*}{$\begin{array}{l}\text { Number of observations } \\
\mathrm{R}^{2}\end{array}$} & 1,994 & 1,994 & 978 & 978 & 1,016 & 1,016 & 1,019 & 1,019 & 975 & 975 \\
\hline & 0.002 & 0.025 & 0.009 & 0.037 & 0.001 & 0.032 & 0.006 & 0.033 & 0.001 & 0.046 \\
\hline & \multicolumn{8}{|c|}{ b. Height for age z-score } & & \\
\hline & \multicolumn{2}{|c|}{ All } & \multicolumn{2}{|c|}{ Girls } & \multicolumn{2}{|c|}{ Boys } & \multicolumn{2}{|c|}{ Urban } & \multicolumn{2}{|c|}{ Rural } \\
\hline & (1a) & (1b) & $(2 a)$ & $(2 b)$ & $(3 a)$ & $(3 b)$ & (4a) & $(4 b)$ & $(5 a)$ & $(5 b)$ \\
\hline \multirow[t]{2}{*}{ Born second semester } & 0.140 & $0.236^{* *}$ & $0.289^{* *}$ & 0.241 & -0.033 & 0.103 & 0.211 & 0.216 & 0.077 & 0.165 \\
\hline & $(0.102)$ & $(0.120)$ & $(0.140)$ & $(0.169)$ & $(0.151)$ & $(0.180)$ & $(0.145)$ & $(0.171)$ & $(0.144)$ & $(0.171)$ \\
\hline \multirow[t]{2}{*}{ Born in 1990} & $0.180^{* *}$ & -0.009 & 0.174 & 0.285 & 0.186 & -0.248 & $0.292^{* *}$ & 0.112 & 0.058 & -0.097 \\
\hline & $(0.089)$ & $(0.162)$ & $(0.129)$ & $(0.212)$ & $(0.124)$ & $(0.256)$ & $(0.124)$ & $(0.294)$ & $(0.127)$ & $(0.236)$ \\
\hline \multirow[t]{2}{*}{ Born second semester * born in 1990} & -0.181 & -0.187 & -0.264 & -0.256 & -0.069 & -0.027 & -0.313 & -0.225 & -0.049 & -0.103 \\
\hline & $(0.136)$ & $(0.132)$ & $(0.188)$ & $(0.184)$ & $(0.200)$ & $(0.197)$ & $(0.197)$ & $(0.192)$ & $(0.189)$ & $(0.190)$ \\
\hline Background controls & NO & YES & NO & YES & NO & YES & NO & YES & NO & YES \\
\hline Number of observations & 1,994 & 1,994 & 978 & 978 & 1,016 & 1,016 & 1,019 & 1,019 & 975 & 975 \\
\hline $\mathrm{R}^{2}$ & 0.002 & 0.115 & 0.005 & 0.074 & 0.003 & 0.059 & 0.005 & 0.079 & 0.001 & 0.045 \\
\hline
\end{tabular}

Notes: Panel A and B present the results of OLS regressions. Robust standard errors are shown in parentheses, while significance levels is $1 \%\left({ }^{* * * *}\right), 5 \%\left({ }^{* * *}\right)$ and $10 \%\left({ }^{*}\right)$.

Background controls include an indicator for the child's gender, child's age in months, two indicator variables for mother's education, two indicator variables for mother's ethnicity, a rural dummy for the place of birth of the child, 8 regions of birth dummies, log of total consumption, number of durables, number of children in the household.

Source: Authors' calculations using the 1994-95 RIHS. 
Table 6. Before-after estimates of the effect of the 1989 abortion legalization on children abandonment A. January 1990 - December 1990

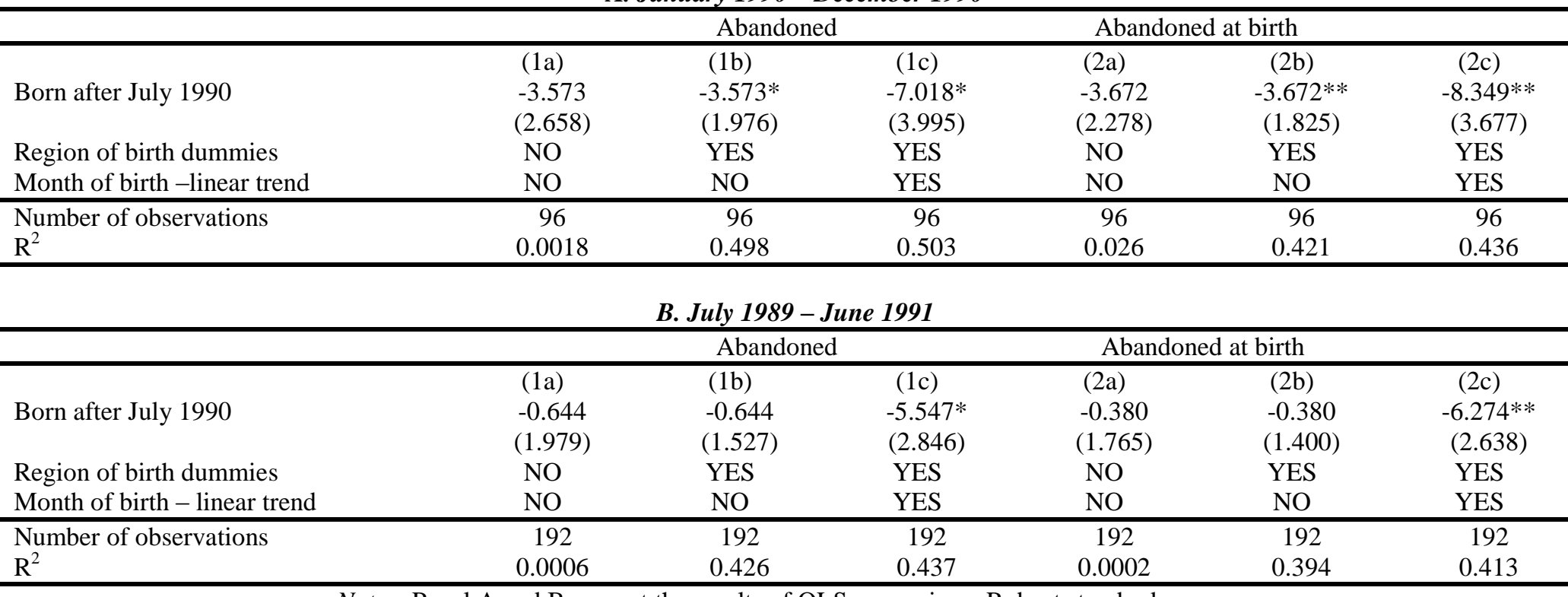

Notes: Panel A and B present the results of OLS regressions. Robust standard errors are shown in parentheses, while significance levels are $1 \%(* * *), 5 \%(* *)$ and $10 \%$ (*).

Source: Authors' calculations using the 1997 Census of the institutionalized children. 
Table 7. Difference-in-difference estimates of the effect of the 1989 abortion legalization on children abandonment

(using the 1990 and 1991 birth cohort)

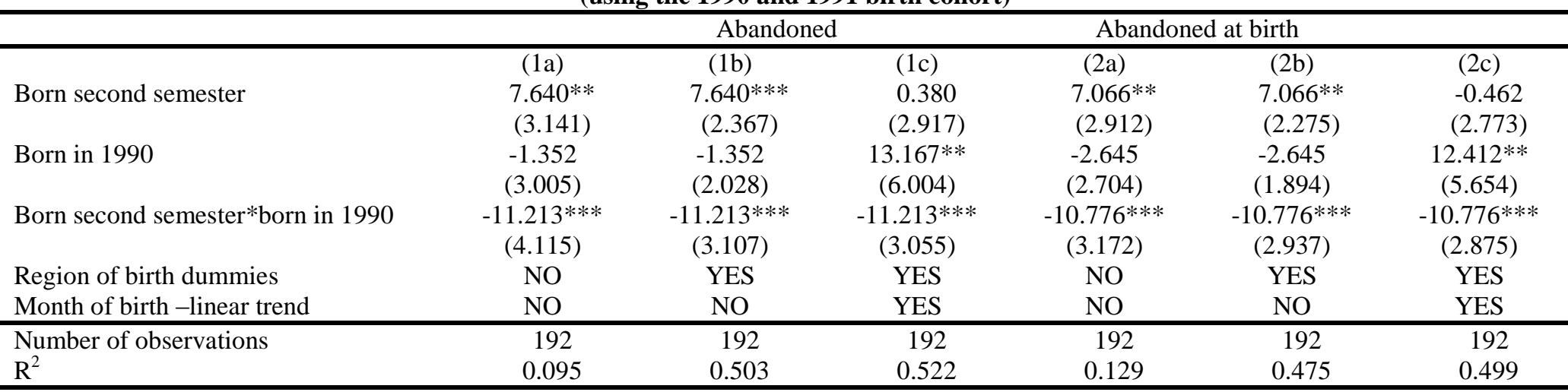

Notes: The table presents results of OLS regressions. Robust standard errors are shown in parentheses, while significance levels are $1 \%(* * *), 5 \%(* *)$ and $10 \%(*)$

Source: Authors' calculations using the 1997 Census of the institutionalized children. 